\title{
Using a two-layered sphere model to investigate the impact of gas vacuoles on the inherent optical properties of Microcystis aeruginosa
}

\author{
M. W. Matthews ${ }^{1,2}$ and S. Bernard ${ }^{1,3}$ \\ ${ }^{1}$ Marine Remote Sensing Unit, Department of Oceanography, University of Cape Town, Rondebosch, \\ 7701, Cape Town, South Africa \\ ${ }^{2}$ Institute for Water Studies, Department of Earth Sciences, University of the Western Cape, Bellville, \\ 7535, Cape Town, South Africa \\ ${ }^{3}$ Earth Systems Earth Observation, Council for Scientific and Industrial Research, 15 Lower Hope Street, Rosebank, \\ 7700, Cape Town, South Africa
}

Correspondence to: M. W. Matthews (mttmar017@myuct.ac.za)

Received: 22 May 2013 - Published in Biogeosciences Discuss.: 27 June 2013

Revised: 1 November 2013 - Accepted: 9 November 2013 - Published: 11 December 2013

\begin{abstract}
A two-layered sphere model is used to investigate the impact of gas vacuoles on the inherent optical properties (IOPs) of the cyanophyte Microcystis aeruginosa. Enclosing a vacuole-like particle within a chromatoplasm shell layer significantly altered spectral scattering and increased backscattering. The two-layered sphere model reproduced features in the spectral attenuation and volume scattering function (VSF) that have previously been attributed to gas vacuoles. This suggests the model is good at least as a first approximation for investigating how gas vacuoles alter the IOPs. Measured $R_{\mathrm{rs}}$ was used to provide a range of values for the central value of the real refractive index, $1+\epsilon$, for the shell layer using measured IOPs and a radiative transfer model. Sufficient optical closure was obtained for $1+\epsilon$ between 1.1 and 1.14 , which had corresponding Chl $a$-specific phytoplankton backscattering, $b_{\mathrm{b} \phi}^{*}$, between 3.9 and $7.2 \times 10^{-3} \mathrm{~m}^{2} \mathrm{mg}^{-1}$ at $510 \mathrm{~nm}$. The $b_{\mathrm{b} \phi}^{*}$ values are in close agreement with the literature and in situ particulate backscattering measurements. $R_{\mathrm{rs}}$ simulated for a population of vacuolate cells was greatly enlarged relative to a homogeneous population. A sensitivity analysis of empirical algorithms for estimating Chl $a$ in eutrophic/hypertrophic waters suggests these are robust under variable constituent concentrations and likely to be species-sensitive. The study confirms that gas vacuoles cause significant increase in backscattering and are responsible for the high $R_{\mathrm{rs}}$ values observed in buoyant cyanobacterial blooms. Gas vacuoles are therefore one of
\end{abstract}

the most important bio-optical substructures influencing the IOPs in phytoplankton.

\section{Gas vacuoles in cyanobacteria: implications for light scattering}

Light scattering by cyanobacteria, especially those exhibiting intracellular gas vacuoles, is poorly described. Prokaryotic cyanobacteria play an important role in the functioning of freshwater and marine ecosystems alongside eukaryotic algae, although their optical properties are less well understood than the latter. These ancient organisms represent a crucial component of Earth's biogeochemical cycling and are hypothesised to have contributed towards the oxygenation of the early atmosphere (Blank and Sánchez-Baracaldo, 2010). Therefore further knowledge of their optical properties will contribute towards an improved understanding of Earth's biogeochemical cycle through their more comprehensive inclusion in ecological and biogeochemical ecosystem models.

Light scattering by planktonic algae and cyanobacteria is profoundly influenced by internal structure (Svensen et al., 2007; Whitmire et al., 2010). Intracellular gas vacuoles are known to have a pronounced effect on the interaction of light with cyanobacteria cells (Dubelaar et al., 1987; Ganf et al., 1989; Volten et al., 1998). Gas vacuoles in cyanobacteria are potentially one of the most important distinctive cellular 
structures influencing the inherent optical properties (IOPs), namely absorption $(a)$, scattering $(b)$, and backscattering $\left(b_{\mathrm{b}}\right)$ (see Table 1 for symbols and definitions used in this paper). Absorption spectra collected using an integrating sphere (which collects all of the forward-scattered light) showed reduced absorption following the collapse of vacuoles in a wavelength-independent fashion (Dubelaar et al., 1987). This is attributed to the loss of light that is scattered in a backward direction by vacuoles, which is confirmed by measurements of isolated collapsed gas vesicles which have insignificant absorption (Waaland et al., 1971; Shear and Walsby, 1975; Walsby, 1994). Therefore intracellular vacuoles probably only lead to a slight increase in true cellular absorption (Ogawa et al., 1979).

Vacuoles have a far greater effect on attenuation than on absorption as a result of strong spectral scattering (see figures in Waaland et al., 1971; Shear and Walsby, 1975; Ogawa et al., 1979; Dubelaar et al., 1987; Ganf et al., 1989; Walsby, 1994). Observations of natural turbid waters dominated by Microcystis spp. indicate that vacuoles may contribute up to $80 \%$ of light scattering (Ganf et al., 1989). Gas vacuoles may scatter up to six times the light scattered by the cell (Fogg et al., 1973). Attenuation is generally increased by the presence of vacuoles (Waaland et al., 1971; Shear and Walsby, 1975; van Liere and Walsby, 1982; Walsby, 1994); however the results of Dubelaar et al. (1987) suggest the changes can be more complex. The difference spectra between vacuolate and non-vacuolate suspensions (which can be attributed to scattering) are typically flat with troughs corresponding to the absorption maxima of cellular pigments (Walsby, 1994; Waaland et al., 1971; Shear and Walsby, 1975). The spectral shapes of the difference curves resemble inverted absorption curves and are similar to scattering spectra of algae (e.g. Bricaud et al., 1983; Zhou et al., 2012). Therefore it appears that vacuoles contained in the cell increase the overall scattering of the cell suspensions equally across the spectrum. This is in contrast to the scattering properties of isolated gas vesicles, which scatter light as Rayleigh scatterers with a $\lambda^{-4}$ shape. When vesicles are packaged within the cell wall in honeycomb-like vacuole arrangements, however, their scattering properties change. This is most likely caused by the increased particle size of vacuole arrangements (Shear and Walsby, 1975).

The effect of gas vacuoles on angular light scatter was examined using flow cytometry by Dubelaar et al. (1987) and Dubelaar and van der Reijden (1995). The collapse of vacuoles in cultured $M$. aeruginosa suspensions increased forward light scatter by a factor of five while simultaneously decreasing perpendicular light scatter by a factor of 10 . The reduced forward light scatter is attributed to a reduction in the real refractive index, $n$, of the cell as a whole as a result of the gas vacuoles. More detailed measurements of the volume scattering function (VSF) of vacuolate and non-vacuolate $M$. aeruginosa cells reveal significant changes in the shape of the VSF (Volten et al., 1998; Schreurs, 1996). Vacuolate cells consistently show a flattening of the VSF in the forward direction, which corresponds to the reduced forward light scatter measured by Dubelaar et al. (1987). This phenomenon is only reproduced by Mie modelling using homogeneous spheres with very low refractive index $(=0.4)$ relative to water (Schreurs, 1996). This confirms that the reduced forward light scatter is caused by vacuoles, which reduce the overall real refractive index of the cell.

There is also evidence that the presence of vacuoles strongly enhances spectral backscattering of cyanobacteria. In comparison with other phytoplankton, vacuolate $M$. aeruginosa is among the most efficient scatterers and is the most efficient backscatterer (Zhou et al., 2012). Matthews et al. (2012) measured a mean Chl $a$-specific particulate backscatter $\left(b_{\mathrm{bp}}^{*}\right)$ in dense $M$. aeruginosa blooms of $0.4 \times 10^{-3} \mathrm{~m}^{-1}$ at $420 \mathrm{~nm}$ and $1.98 \times 10^{-3} \mathrm{~m}^{-1}$ at $700 \mathrm{~nm}$ $(N=13)$. These were an order of magnitude larger than similar measurements made in a high-biomass dinoflagellate marine bloom and are in the upper range of values present in the literature (e.g. Whitmire et al., 2010; Ahn et al., 1992). The enhanced backscatter can be partially attributed to the small cell size, but must be overwhelmingly attributed to intracellular vacuoles since $M$. aeruginosa has no other unusual substructure or shape variation (spherical) to distinguish it from algae. Unfortunately Zhou et al. (2012) did not measure the backscatter of non-vacuolate cells. Until the present study, no detailed modelling study has been undertaken to demonstrate the effect vacuoles might have on the IOPs of cyanobacteria.

\subsection{Composition, morphology, and cellular arrangement of gas vacuoles}

Gas vacuoles are composed of individual gas vesicles which are stacked length-wise in a hexagonal honeycomb-type arrangement within the cytoplasm (see review by Walsby, 1994). These vesicles are cylindrical membrane tubes composed entirely of proteins and capped on each end with a half-cone. In Microcystis, individual vesicles have width and height of approximately 70 and $360 \mathrm{~nm}$, respectively, while the membrane wall is approximately $2 \mathrm{~nm}$ thick (Jost and Jones, 1970). Waaland et al. (1971) found a peripheral cellular arrangement of vacuoles in Nostoc cells, as was observed in the marine cyanobacterium Trichodesmium (van baalen and Brown, 1969). The peripheral arrangement of vacuoles has caused speculation of light shielding of the photosynthetic lamella (e.g. van baalen and Brown, 1969; Rajagopal et al., 2005); however this is somewhat disputed (Ogawa et al., 1979). Polar arrangement is observed in Pseudanabaena, while both central and polar arrangements exist in Oscillatoria species (Meffert et al., 1981). In M. aeruginosa, peripheral (Jost and Jones, 1970) and random (Jost and Zehnder, 1966; Šmarda, 2009) arrangements are observed. The main factor affecting the cellular arrangement of vacuoles appears to be the light conditions, with some evidence that high 
Table 1. Symbols and definitions.

\begin{tabular}{|c|c|c|}
\hline Symbol & Definition & Unit \\
\hline$m$ & Complex refractive index & \\
\hline$n$ & Real refractive index & \\
\hline$n^{\prime}$ & Imaginary refractive index & \\
\hline$n_{\mathrm{W}}$ & Real refractive index for water & \\
\hline$n_{m}$ & Homogeneous real refractive index & \\
\hline $1+\epsilon$ & The central value of $n$ & \\
\hline$\Delta n$ & The variation of $n$ around $1+\epsilon$ & \\
\hline$d$ & Diameter & $\mu \mathrm{m}$ \\
\hline$r_{\text {eff }}$ & Effective radius & $\mu \mathrm{m}$ \\
\hline$V_{\text {eff }}$ & Effective variance & \\
\hline$V_{\mathrm{g}}$ & Gas vacuole volume & \\
\hline$V_{\mathrm{c}}$ & Core layer volume & \\
\hline$V_{\mathrm{s}}$ & Shell layer volume & \\
\hline$c_{\mathrm{i}}$ & Intracellular Chl $a$ concentration & $\mathrm{kg} \mathrm{m}^{-3}$ \\
\hline$a$ & Absorption coefficient & $\mathrm{m}^{-1}$ \\
\hline$b$ & Scattering coefficient & $m^{-1}$ \\
\hline$c$ & Attenuation coefficient & $m^{-1}$ \\
\hline$b_{\mathrm{b}}$ & Backscattering coefficient & $\mathrm{m}^{-1}$ \\
\hline$a_{\phi}^{*}$ & Chl $a$-specific phytoplankton absorption coefficient & $\mathrm{m}^{2} \mathrm{mg}^{-1}$ \\
\hline$b_{\phi}^{*}$ & Chl $a$-specific phytoplankton scattering coefficient & $\mathrm{m}^{2} \mathrm{mg}^{-1}$ \\
\hline$b_{\mathrm{b} \phi}^{*}$ & Chl $a$-specific phytoplankton backscattering coefficient & $\mathrm{m}^{2} \mathrm{mg}^{-1}$ \\
\hline$a_{\mathrm{tr}}^{*}$ & Tripton mass-specific absorption coefficient & $\mathrm{m}^{2} \mathrm{~g}^{-1}$ \\
\hline$b_{\mathrm{tr}}^{*}$ & Tripton mass-specific scattering coefficient & $\mathrm{m}^{2} \mathrm{~g}^{-1}$ \\
\hline$b_{\mathrm{btr}}^{*}$ & Tripton mass-specific backscattering coefficient & $\mathrm{m}^{2} \mathrm{~g}^{-1}$ \\
\hline$a_{\mathrm{g}}$ & Gelbstoff absorption coefficient & $\mathrm{m}^{-1}$ \\
\hline$a_{\mathrm{W}}$ & Water absorption coefficient & $m^{-1}$ \\
\hline$b_{\mathrm{bp}}$ & Particulate backscattering coefficient & $\mathrm{m}^{-1}$ \\
\hline$b_{\mathrm{bp}}^{*}$ & Chl $a$-specific particulate backscattering coefficient & $\mathrm{m}^{2} \mathrm{mg}^{-1}$ \\
\hline$\tilde{b}_{\mathrm{b}}$ & Backscattering ratio & \\
\hline$\tilde{b}_{\mathrm{f}}$ & Forward scattering ratio & \\
\hline$Q_{\mathrm{a}}$ & Optical efficiency factor for absorption & \\
\hline$Q_{\mathrm{b}}$ & Optical efficiency factor for scattering & \\
\hline$Q \mathrm{c}$ & Optical efficiency factor for attenuation & \\
\hline $\bar{Q}_{\mathrm{a}}$ & The experimental mean absorption efficiency factor & \\
\hline$Q_{\mathrm{c}}^{\mathrm{NAE}}$ & The non-absorbing efficiency factor for attenuation & \\
\hline$R_{\mathrm{rs}}$ & Remote sensing reflectance & $\mathrm{sr}^{-1}$ \\
\hline$\beta$ & Phase function & $\mathrm{m}^{-1} \mathrm{sr}^{-1}$ \\
\hline
\end{tabular}

light favours a peripheral location (see Shear and Walsby, 1975; Walsby, 1994).

The ratio of gas vacuole to cell volume, $V_{\mathrm{g}}: V_{\mathrm{c}}$, also appears to be regulated by light as well as nutrient availability (Walsby, 1994). Density calculations for various cyanobacteria show that the volume occupied by vacuoles in order to make the cell neutrally buoyant varies from 3 to $10 \%$. However, studies show that the actual volume occupied by vacuoles is often substantially higher than this. The volume occupied by vesicles in cultured $M$. aeruginosa in logarithmic growth phase was $5.8 \mu^{3}$ per cell, which equates to $V_{\mathrm{g}}: V_{\mathrm{c}}=$ approximately $8 \%$ (assuming a cell radius $=2.58 \mu \mathrm{m})($ Lehmann and Jost, 1971). Gas vacuoles ex- ist throughout the life cycle of $M$. aeruginosa in variable amounts, reaching $>90 \%$ of the cell volume in peak summer (Šmarda, 2009). Vacuoles are even present in the benthic overwintering stage in relatively high volumes $\left(V_{\mathrm{g}}: V_{\mathrm{c}}=\right.$ 1.8-2.9\%) (Reynolds et al., 1981).

One of the primary consequences of vacuolation is lowering of cellular density (providing buoyancy) and therefore the overall real refractive index. The refractive index of the vacuole is close to 0.825 , while that of the other cellular material is close to 1.028 relative to the medium (water) (Fuhs, 1969). This change in refractive index has substantial implications for how light interacts with the cell (Shear and Walsby, 1975; Porter and Jost, 1976; Dubelaar et al., 1987). 
Using the concept of a significant refractive index and the Gladstone-Dale volume-equivalence formulation, the overall or homogeneous refractive index, $n_{m}$, can be calculated from its parts according to $n_{m}=\sum_{j} n_{j} v_{j}$, where $v$ is the relative volume and $j$ is the number of components (Aas, 1996). Increasing the vacuole content leads to a concentration of cellular material as vacuoles occupy space within the cytoplasm (Raven, 1987). Calculating the homogeneous refractive index of the cell using the values of Fuhs (1969) for the gas vacuole and chromatoplasm and $V_{\mathrm{g}}: V_{\mathrm{c}}$ ranging from 2 to $90 \%$ gives $n_{m}$ varying over a considerable range between 1.02 and 0.84 relative to water. This demonstrates the considerable effect gas vacuolation may have on $n_{m}$. A detailed calculation of the complex refractive index, $m$, for the gas vacuole and chromatoplasm is performed in Sect. 2.2.

\subsection{The two-layered sphere model approximation}

Lorenz-Mie modelling using a population of homogeneous spheres has been used extensively to model phytoplankton IOPs (e.g. Stramski et al., 2001). However, this approach is often criticised as being overly simplistic since phytoplankton differ considerably in shape and internal structure from homogeneous spheres. Recent comparisons between Mie modelling and experimental results demonstrate the limitations of this approach to sufficiently simulate phytoplankton IOPs (e.g. Zhou et al., 2012; Whitmire et al., 2010). An alternative approach is therefore required to account for variation in internal structure (and shape) of phytoplankton cells. Two-layered and three-layered sphere models which simulate internal structures of the cell wall, the cytoplasm, and or the chloroplast can more adequately simulate phytoplankton IOPs (e.g. Quinby-Hunt et al., 1989; Kitchen and Zaneveld, 1992; Bernard et al., 2009). In particular the AdenKerker two-layered sphere is probably the simplest geometrical arrangement capable of reproducing experimental IOPs (Quirantes and Bernard, 2006). The suitability of such a twolayered Aden-Kerker model for investigating the optical consequences of gas vacuoles is evaluated here.

The cellular arrangement of cyanobacteria and M. aeruginosa in particular provides a unique opportunity for the twolayered model to investigate the influence of vacuole substructure. The traditional assignment of the two spherical layers of the model to chloroplast and cytoplasm, respectively (e.g. Bernard et al., 2009) is less suitable to prokaryotic cyanobacteria. The thylakoids in cyanobacteria are not arranged in strict membrane-bound chloroplasts but rather occur in the intracytoplasmic membrane towards the periphery of the cell (the so-called chromatoplasm). Given this cellular arrangement, the opportunity arises for the core layer to be assigned to a vacuole-like particle, while assigning the shell layer to that containing the photosynthetic thylakoids and the cytoplasm. This is based on the assumption that the vacuole can be adequately simulated as a single homogeneous particle of spherical shape. However, the shape and organisation of the vacuole might actually lend itself to such an approximation. In comparison with isolated vesicles, the vacuole is more irregular and in some cases spherical in shape owing to vesicle stacking, organised in the cell in one or more discrete packages, and much larger than the tiny individual vesicles (up to $3.5 \mu \mathrm{m}$ in diameter by volume calculation) (see figures in Šmarda, 2009; Reynolds et al., 1981). Therefore vacuoles behave as larger optical units (Shear and Walsby, 1975) and might be sufficiently approximated by a spherical core layer.

\subsection{M. aeruginosa: a representative prototype for modelling}

M. aeruginosa is a ubiquitous cyanophyte responsible for much of the concern related to toxin production from cyanoblooms in freshwaters. Worldwide it represents a prolific species of great relevance to environmental monitoring and remote sensing applications. Its morphological characteristics - spherical shape, relatively small size, high vacuole content - make it well suited to modelling studies based on spherical geometries and for testing theories related to how vacuoles might affect the IOPs. Previous IOP modelling studies of cyanophytes have mainly been restricted to small marine species (picoplankton) (e.g. Synechococcus), which is useful because they are assumed to generally obey the assumptions of Mie theory (e.g. Morel and Bricaud, 1986; Morel et al., 1993; Stramski et al., 2001). However, these are not representative of the genera. There therefore seems to be a paucity in detailed IOP studies of the cyanobacteria, especially for larger ubiquitous freshwater species, e.g. Microcystis or Dolichospermum. The prolific occurrence of M. aeruginosa blooms in South African reservoirs make it a convenient species for studies using natural populations. It therefore represents a convenient prototype for optical modelling while simultaneously being of great relevance to environmental applications owing to its abundance.

The existence of $M$. aeruginosa in nature in colonial arrangements undoubtedly has significant implications for its IOPs, especially when considering absorption effects related to the package effect (Kirk, 1975; Agusti and Phlips, 1992). Microcystis cells form colonies with great variability in size and shape, and cell densities can be as high as 3-5 cells per $1000 \mu^{3}$ (Reynolds et al., 1981). Analysing colony size using flow cytometry, Dubelaar and van der Reijden (1995) found that colonies appear to behave as a collection of individual cells rather than as larger discrete optical units (see Fig. 1 therein). While the geometries used in flow cytometry are appreciably different from nature, for the purposes of this study it is assumed that $M$. aeruginosa blooms can be modelled as a population of single cells.

The aim of this paper is to test the hypothesis that gas vacuoles significantly alter the IOPs of $M$. aeruginosa by causing large changes in scattering. The study begins by investigating the effects of containing a gas-vacuole-like particle within a two-layered sphere on the optical efficiency 
factors, Chl $a$-specific IOPs, and VSF of M. aeruginosa. The potential influence and contribution of gas vacuole to the higher-than-usual $R_{\mathrm{rs}}$ signals observed in blooms of vacuolate cyanophytes is then investigated using a suite of in situ experimental data of the IOPs and $R_{\mathrm{rs}}$, as well as a radiative transfer model. A range of plausible $n$ values for the shell chromatoplasm layer are therefore determined, along with the corresponding $\mathrm{Chl} a$-specific backscattering for $M$. aeruginosa.

\section{Methods}

\subsection{Study area and in situ data}

In situ measurements were performed at Hartbeespoort Dam, South Africa, in October 2010 on spring blooms of M. aeruginosa, which made up more than $90 \%$ of the population as percentage as determined by microscopy. Background information on Hartbeespoort as well as details of sampling strategy, locations, and methods can be found in Matthews and Bernard (2013). The M. aeruginosa blooms existed at very high biomass as aggregated colonial surface accumulations (scum) with Chl $a$ ranging from 70 to $1503 \mathrm{mg} \mathrm{m}^{-3}$ with a mean value of $404 \mathrm{mg} \mathrm{m}^{-3}$. Given the extremely high biomass, the water might effectively be treated as a "culture", eliminating some of the complexity as far as optical modelling is concerned (Matthews and Bernard, 2013).

$\mathrm{Chl} a$ was determined in triplicate spectrophotometrically by extraction in boiling ethanol (Sartory and Grobbelaar, 1984). The quantitative filter pad technique was used to determine the spectral absorption coefficients of particulate matter between 350 and $850 \mathrm{~nm}$ using a Shimadzu UV-2501 spectrometer fitted with an integrating sphere (Mitchell et al., 2003). The pigmented component was determined by sodium hypochlorite bleaching. The Whatman GF/F filter pad was assumed to be completely diffuse $(\beta=2)$ (Roesler, 1998). The integrating sphere collects almost all of the forwardscattered light; however it does not account for the loss by backscatter, which may be caused by vacuoles (Dubelaar et al., 1987). However, no attempt was made to correct the absorption measurements for backscatter by vacuoles but its effects are investigated (Sect. 3.1). The Chl $a$-specific phytoplankton absorption coefficient $\left(a_{\phi}^{*}\right)$ was calculated as the pigmented component divided by $\mathrm{Chl} a$. The concentration and absorption properties of tripton (TR) and gelbstoff were determined as described in Matthews and Bernard (2013). TR ranged from 1.7 to $19.8 \mathrm{~g} \mathrm{~m}^{-3}$, while $a_{\mathrm{g}}(442)$ ranged between 0.17 and $2.04 \mathrm{~m}^{-1}$, with an exponential slope coefficient determined as $0.017 \mathrm{~m}^{-1}$.

$R_{\mathrm{rs}}$ was measured using an ASD FieldSpec3 (ASD Inc.) using the measurement geometry of Mueller et al. (2003). Briefly, 10 radiance spectra were collected in sequence for Spectralon $^{\mathrm{TM}}$, sky, and water targets. Taking care to exclude contaminated or outlying spectra, the mean of the radiance spectra for each target was computed, from which an $R_{\mathrm{rs}}$ spectrum was calculated. This procedure was performed in triplicate at each site, with the final $R_{\mathrm{rs}}$ spectrum determined as the mean. Measurements were made under mostly clearsky conditions (cloud cover $<20 \%$ ) to avoid errors from shadows and diffuse sky light (Doxaran et al., 2004).

The depth-specific particulate backscattering coefficient, $b_{\mathrm{bp}}(z)$, was measured at 440 and $700 \mathrm{~nm}$ using a Hydroscat 2 (Hobilabs Inc.). Depth profiles ranging from the surface to a depth of approximately $5 \mathrm{~m}$ were binned, median filtered to reduce noise, re-sampled and interpolated to $10 \mathrm{log}$-spaced depth bins between $0.8 \mathrm{~m}$ and the maximum depth using nearest-neighbour interpolation. The profiles were measured simultaneous to $R_{\mathrm{rs}}$ and $\mathrm{Chl} a$ measurements, and the $\mathrm{Chl} a$ specific particulate backscattering coefficients, $b_{\mathrm{bp}}^{*}$, were calculated using $b_{\mathrm{bp}}$ at $z=0.8 \mathrm{~m}$ and surface $\mathrm{Chl} a$ measurements. Profiles measured in $\mathrm{Chl} a>1500 \mathrm{mg} \mathrm{m}^{-3}$ were excluded.

\subsection{Complex refractive index of $M$. aeruginosa}

The details of Mie and Aden-Kerker theory of light scattering with small particles may be found in Morel and Bricaud (1986) and Bernard et al. (2009). Briefly, the complex refractive index $(m)$ is composed of real $(n)$ and imaginary parts $\left(n^{\prime}\right)$ according to $m=n-i n^{\prime} . n$ is said to vary according to $1+\epsilon+\Delta n$ where $1+\epsilon$ is the central value around which $n$ varies and $\Delta n$ is the spectral variation as predicted by the Kramers-Kronig or Ketteler-Helmholtz theories. $n$ is provided relative to water as $n=n / n_{\mathrm{w}}$, where $n_{\mathrm{w}}$ is $1.334 . m$ for phytoplankton may be determined from spectral absorption and particle size distribution (PSD) measurements using an inverse anomalous diffraction approximation (ADA) model (Bricaud and Morel, 1986; Ahn et al., 1992). This is based on the ADA assumption that the value of $1+\epsilon$ relative to the medium (water) is close to 1 (i.e. $1+\epsilon \approx 1.334$ ). This assumption is generally valid for phytoplankton (Aas, 1996). While heavily vacuolate cells violate this assumption, it should be valid for non-vacuolate cells. Since vacuoles have an insignificant effect on true cellular absorption used by the method, an initial value for the refractive index of a homogeneous $M$. aeruginosa cell consisting of chromatoplasm and centroplasm (minus effects of gas vacuoles) was determined using the method of Bricaud and Morel (1986) as modified by Bernard et al. (2001).

The PSDs of $M$. aeruginosa were not measured due to difficulties associated with the colonial arrangement of the cells and their existence at extremely high biomass in a surface scum layer. Therefore, a log-normal distribution of cells with diameters ranging from 3.2 to $8 \mu \mathrm{m}$ was used to estimate the PSD for $M$. aeruginosa. The size range is based on measurements of individual $M$. aeruginosa cells previously made in Hartbeespoort Dam (Robarts et al., 1984). The distribution was expressed in terms of the effective variance $\left(V_{\text {eff }}\right)$ and radius $\left(r_{\text {eff }}\right)$ (Bernard et al., 2007), which were 
set to 0.02 and $2.58 \mu \mathrm{m}$, respectively. The log-normal distribution is generally suitable for representing mono-specific phytoplankton blooms (Bricaud and Morel, 1986; Ahn et al., 1992). The size distribution was scaled to give $1 \mathrm{mg} \mathrm{Chl} a$ for the phytoplankton population (or the Chl $a$-specific PSD) using an intracellular chlorophyll density $\left(c_{\mathrm{i}}\right)$. The $c_{\mathrm{i}}$ value has large implications for $n^{\prime}$, the absorption and scattering efficiencies $\left(Q_{\mathrm{a}}, Q_{\mathrm{b}}\right)$, and the Chl $a$-specific volume coefficients (Morel and Bricaud, 1986). Therefore an appropriate value for $c_{\mathrm{i}}$ must be chosen with care. Values for $c_{\mathrm{i}}$ for $M$. aeruginosa previously measured are $2.1 \mathrm{~kg} \mathrm{~m}^{-3}$ (Zhou et al., 2012), $3.2 \mathrm{~kg} \mathrm{~m}^{-3}$ (Agusti and Phlips, 1992), and $4.5 \mathrm{~kg} \mathrm{~m}^{-3}$ (Reynolds et al., 1981). These were computed from cellular volumes and Chl $a$ concentrations presented in the references and fall within the upper range of accepted values for phytoplankton (e.g. Morel and Bricaud, 1986). Values for marine pico-cyanobacteria are typically less than this around 1.15$1.78 \mathrm{~kg} \mathrm{~m}^{-3}$. The lowest $c_{\mathrm{i}}$ value of $2.1 \mathrm{~kg} \mathrm{~m}^{-3}$ was selected after analysing results produced by the different values, as discussed in Sect. 3.4.

The experimental mean absorption efficiency factor, $\bar{Q}_{\mathrm{a}}$, for $M$. aeruginosa was then calculated between 360 and $850 \mathrm{~nm}$ using the estimated Chl $a$-specific PSD and $a_{\phi}^{*}$ (Morel and Bricaud, 1986). $n^{\prime}$ was then calculated by fitting the experimental $\bar{Q}_{\mathrm{a}}$ to that modelled using the ADA. $\Delta n$, was determined as a Hilbert transform of $n^{\prime}$ according to the Kramers-Kronig theory of anomalous dispersion (Bernard et al., 2001). An initial value for $1+\epsilon$ was then determined by convergence of the modelled efficiency factors for attenuation $\left(Q_{\mathrm{c}}\right)$ and for the non-absorbing equivalent $\left(Q_{\mathrm{c}}^{\mathrm{NAE}}\right)$. The $1+\epsilon$ value was selected at the wavelength where $n^{\prime}$ was smallest. This technique was used given the absence of further scattering or attenuation data. A range of plausible $1+\epsilon$ chromatoplasm values were also determined, as described in Sect. 2.5.

\subsection{Complex refractive indices of gas vacuoles}

Using interference microscopy Fuhs (1969) estimated $n=0.80$ for vacuole and $n=1.028$ for the surrounding cytoplasm relative to water. The calculations of Fuhs (1969) included the volumes of air, protein membrane, and interstitial cytoplasmic material. The spectral refractive index for a hypothetical gas vacuole was calculated using a volumeequivalent approach (Gladstone-Dale). Calculations were performed using the mean geometries for Microcystis vesicles given by Jost and Jones (1970) (length $=360 \mathrm{~nm}$, diameter $=70 \mathrm{~nm}$, wall thickness $=1.8 \mathrm{~nm})$ and an assumed packing efficiency of $15 \%$ (Walsby, 1994). Using these geometries, the relative volume for interstitial cytoplasm (water), air, and proteins was calculated as $0.15,0.76$, and 0.09 , respectively. The spectral real and imaginary refractive indices for the lipid-free protein Ovalbumin (Arakawa et al., 2001) were used for the protein membrane. These data are similar to values reported elsewhere for proteins $(n=1.20$ and $n^{\prime}=1 \times 10^{-5}$; Aas, 1996) and are generally representative of lipid-free proteins. Detailed spectral refractive index data for water and air were taken from Ciddor (1996) and Hale and Querry (1973), respectively.

\subsection{Parameterisation of the two-layered sphere model}

A two-layered sphere model using the Aden and Kerker (1951) formulation and the code of Toon and Ackerman (1981) were used to calculate the IOPs (after Bernard et al., 2009) in a Fortran/Matlab environment (The MathWorks ${ }^{\mathrm{TM}}$ ). Inputs to the model are the radius of the core and shell layers, $m$ for the core and shell layers, the wave number (wavelength), and angular resolution (which is $0.1^{\circ}$ ). The output is the dimensionless angular intensity parameters $\left(i_{1}\right.$ and $\left.i_{2}\right)$ and the efficiency factors for attenuation and scattering $\left(Q_{\mathrm{b}}\right)$ from which the phase function $(\beta)$, the backscattering probability $\left(\tilde{b_{\mathrm{b}}}\right)$, and the absorption and backscattering efficiencies $\left(Q_{\mathrm{a}}, Q_{\mathrm{bb}}\right)$ can be calculated (see Morel and Bricaud (1986) for calculations). Using the PSD and $m$ for shell and core layers, the bulk IOPs $\left(a, b\right.$, and $\left.b_{\mathrm{b}}\right)$ for the cell population were calculated at a $5 \mathrm{~nm}$ wavelength resolution.

The core and shell layers were assigned to the vacuole and chromatoplasm, respectively. By assigning the layer with the higher refractive index to be the outer layer, the effect of the cell wall membrane which is known to have a great impact on scattering (Quinby-Hunt et al., 1989; Svensen et al., 2007) is more adequately simulated. Furthermore, in cyanobacteria, the photosynthetic thylakoids are most often arranged in concentric anastomosing shells parallel to the cell wall (Golecki and Drews, 1982), and this kind of arrangement with some additional irregularity is observed in M. aeruginosa (Šmarda, 2009). The sometimes peripheral arrangement of gas vacuoles is not without enclosure by the layered cell wall membrane, and a random arrangement within the centroplasm is more frequently observed in M. aeruginosa. This favours a core assignment for the vacuole which may even be surrounded by the photosynthetic lamella (Smith and Peat, 1967).

The effects of altering the relative volume occupied by the gas vacuole, $V_{\mathrm{g}}$, on the IOPs is investigated. The relative volumes of the core, $V_{\mathrm{c}}\left(=V_{\mathrm{g}}\right)$, and shell, $V_{\mathrm{s}}$, layers were adjusted according to $V_{\mathrm{c}}=1-V_{\mathrm{s}}$. The core radius, $r_{\mathrm{c}}$, may be calculated using the shell radius, $r_{s}$, and $V_{\mathrm{c}}$ by $r_{\mathrm{c}}=r_{\mathrm{s}} V_{\mathrm{c}}^{1 / 3}$. Considering relative gas vacuole volumes in the range $1-50 \%$, and a population of cells with diameters between 3.2 and $8.0 \mu \mathrm{m}$, the diameters of the spherical core vacuole would range between 0.68 and $6.34 \mu \mathrm{m}$. This represents a particle in the realm of Mie scattering, with a minimum diameter comparable to the wavelength of visible light $(680 \mathrm{~nm})$, and in the anomalous diffraction domain.

It has been shown that the cell volume remains unchanged when gas vesicles are collapsed by pressurisation (Porter and Jost, 1976; Dubelaar et al., 1987). The synthesis of vesicles within the cell therefore decreases the relative volume 
occupied by the chromatoplasm, leading to a concentration effect on the absorbing material, assuming that the amount of absorbing material in the cell $\left(c_{\mathrm{i}}\right)$ remains constant. This effect must be accounted for in calculations when altering the relative volumes of core and shell layers. The equation relevant to a two-layered geometry relating $n^{\prime}$ to $c_{\mathrm{i}}$ and the relative shell volume, $V_{\mathrm{s}}$, is given by Bernard et al. (2009):

$n_{\text {chrom }}^{\prime}(675)=\frac{675}{n_{\text {media }}} \frac{c_{\mathrm{i}} a_{\text {sol }}^{*}(675)}{\pi 4 V_{\mathrm{s}}}$,

where $n_{\text {media }}=1.334$ and $a_{\mathrm{sol}}^{*}(675)$ is the theoretical maximum absorption by unpackaged $\mathrm{Chl} a$.

This scales the $n^{\prime}$ at $675 \mathrm{~nm}$ by the maximum theoretical absorption of unpackaged Chl $a$, keeping the amount of absorbing material in the cell constant. The value for $a_{\mathrm{sol}}^{*}(675)$ is given by Johnsen et al. (1994) as $0.027 \mathrm{mg}^{-1} \mathrm{~m}^{-2}$, which is applicable to cyanobacteria (Bidigare et al., 1989).

\subsection{Optical closure for M. aeruginosa using the two-layered model}

The availability of the suite of in situ optical/biogeochemical data from the high-biomass mono-specific natural M. aeruginosa blooms in Hartbeespoort provides an opportunity to perform a detailed investigation of the optical properties of M. aeruginosa. For the data set used here, $a_{\phi}$ composed a mean of $85 \%$ (up to $98 \%$ ) of the total absorption and $96 \%$ (up to $99 \%$ ) of the particulate absorption at $442 \mathrm{~nm}$ (see Fig. 18 in Matthews and Bernard (2013)). $a_{\phi}(442)$ had a mean value of $18 \mathrm{~m}^{-1}$, while the corresponding mean values for $a_{\mathrm{tr}}$ and $a_{\mathrm{g}}$ were 0.3 and $1.1 \mathrm{~m}^{-1}$. Therefore, from an optical perspective, $M$. aeruginosa is the overwhelmingly dominant contributor to the total absorption and scattering, with negligible or small contributions from tripton (nonphytoplankton) and dissolved components.

Neglecting the contribution of viruses, bubbles, and other small particles (Stramski et al., 2001), a four-component biooptical model consisting of phytoplankton, tripton, gelbstoff, and water, was used to forward model the $R_{\mathrm{rs}}$ using a direct solution of the equation of radiative transfer in Ecolight-S (E-S, V1.0 $0^{\odot}$ Sequoia Scientific). The inputs to E-S are the total IOPs $\left(a_{\mathrm{t}}, b_{\mathrm{t}}, b_{\mathrm{bt}}\right)$ and the downwelling irradiance. As $a_{\mathrm{t}}$ is known (or measured), the only unknowns in the forward model are (back)scattering for phytoplankton and tripton, assuming gelbstoff is non-scattering. Given the negligible contribution of tripton to particulate absorption and scattering, the only optically significant unknowns are the (back)scattering from $M$. aeruginosa, which in this case are estimated using the two-layered model. The data therefore provide an opportunity to investigate optical closure with regards $M$. aeruginosa using (back)scattering as determined by the two-layered model.

With regards to the two-layered model, assuming that the core vacuole layer $m$ value is constant with a volume of $50 \%$, and the $n^{\prime}$ value for the chromatoplasm is adequately deter- mined, the only unknowns in the two-layered configuration are the shell layer $1+\epsilon$ value and in this case the estimated PSD. Tests showed that variations in the PSD had small effects on the two-layer determined IOPs and resulting $R_{\mathrm{rs}}$. Decreasing $D_{\min }$ or increasing $D_{\max }$ while holding $V_{\text {eff }}$ constant had negligible effects. Increasing $V_{\text {eff }}$ to 0.1 while simultaneously decreasing $D_{\min }$ to $1 \mu \mathrm{m}$ or increasing $D_{\max }$ to $15 \mu \mathrm{m}$ had small but noticeable effects resulting in a maximum change in $R_{\mathrm{rs}}$ at $\mathrm{Chl} a$ of $100 \mathrm{mg} \mathrm{m}^{-3}$ of approximately $12 \%$. Therefore there is a relatively small sensitivity to the width and size range of the PSD in $R_{\mathrm{rs}}$.

Assuming the estimated PSD is acceptable, the only remaining unknown is the shell layer $1+\epsilon$ value. At the high biomass observed in this study, the $R_{\mathrm{rs}}$ was found to be very sensitive to the chromatoplasm $1+\epsilon$ value. Comparing values of 1.08 and 1.15 for the chromatoplasm, the corresponding $b_{\mathrm{b} \phi}^{*}$ increased over $370 \%$, which resulted in a $300 \%$ increase in $R_{\mathrm{rs}}$ for a constant $\mathrm{Chl} a$ value of $100 \mathrm{mg} \mathrm{m}^{-3}$. Therefore, for the high-biomass conditions and model configuration used here, the magnitude of $R_{\mathrm{rs}}$ is found to be primarily controlled by the shell $1+\epsilon$ value.

Initial tests using the $1+\epsilon$ chromatoplasm value determined after Bernard et al. (2001) resulted in $b_{\mathrm{b} \phi}$ values substantially lower than literature values as well as underestimates of $R_{\mathrm{rs}}$ as determined by forward simulations using $\mathrm{E}-$ $\mathrm{S}$. Thus optical closure could not be achieved using the initially determined $1+\epsilon$ value, suggesting that a higher value might be more appropriate. Therefore, in order to achieve optical closure of the experiment, the chromatoplasm $1+\epsilon$ value was allowed to vary in the range 1.04 to 1.15 at a 0.001 interval. This range of values is in agreement with values for eukaryotic chloroplasts (Bernard et al., 2009), which are likely equivalent to a prokaryotic chromatoplasm and therefore likely to be acceptable from an optical perspective. The resulting $b_{\mathrm{b} \phi}^{*}$ and $b_{\phi}^{*}$ generated by the two-layer model were added to a look-up table (LUT).

The forward model was then allowed to select appropriate values for $b_{\mathrm{b} \phi}^{*}$ and $b_{\phi}^{*}$ from the LUT in order to provide the best fit with the measured $R_{\mathrm{rs}}$ solved using a non-linear Nelder-Mead simplex algorithm. In this way a range of appropriate values for the chromatoplasm $1+\epsilon$ value was determined which provided appropriate optical closure for the $R_{\mathrm{rs}}$. Eight $R_{\mathrm{rs}}$ spectra for which absorption coefficients (in duplicate), biogeochemical parameters (in triplicate), and atmospheric parameters were coincidentally measured were used.

The bio-optical model for the forward model was configured as

$a_{\mathrm{t}}=\mathrm{Chl} a \times a_{\phi}^{*}+\mathrm{TR} \times a_{\mathrm{tr}}^{*}+a_{\mathrm{g}}+a_{\mathrm{w}}$,

$b_{\mathrm{t}}=\mathrm{Chl} a \times b_{\phi}^{*}+\mathrm{TR} \times b_{\mathrm{tr}}^{*}+b_{\mathrm{w}}$,

$b_{\mathrm{bt}}=\mathrm{Chl} a \times b_{\mathrm{b} \phi}^{*}+\mathrm{TR} \times b_{\mathrm{btr}}^{*}+b_{\mathrm{bw}}$,

where subscript $\mathrm{w}$ stands for water.

All components in the forward bio-optical model were calculated using measured values for $\mathrm{Chl} a$, TR, and $a_{\mathrm{g}}$ for 
each sample. $a_{\mathrm{w}}$ and $b_{\mathrm{w}}\left(b_{\mathrm{bw}}=1 / 2 b_{\mathrm{w}}\right)$ were taken from Rottgers et al. (2011). The mass-specific tripton absorption, $a_{\mathrm{tr}}^{*}$, used was $0.037 e^{-0.010(\lambda-442)}$ as determined by Matthews and Bernard (2013). The corresponding tripton mass-specific (back)scattering coefficients, $b_{\mathrm{tr}}^{*}$ and $b_{\mathrm{btr}}^{*}$, were estimated using a Mie model and an inverse ADA model (see Bricaud and Morel (1986) for calculations). The tripton mass-specific PSD was computed from $a_{\mathrm{tr}}^{*}$ and an estimate of $n^{\prime}=0.01 \exp (-0.007 \lambda)$ (Stramski and Wozniak, 2005) (note that the original equation given in Stramski et al. (2001) is incorrect). The tripton PSD was assumed to obey a Jungian distribution with slope $\gamma=-4$ and diameters between 1 and $100 \mu \mathrm{m}$ in log-spaced bins. Mie calculations of homogeneous spheres were then used to compute $b_{\mathrm{tr}}^{*}$ and $b_{\mathrm{btr}}^{*}$ with the mass-specific tripton PSD and $n^{\prime} . n$ for tripton particles was set to 1.05 , assuming a $90 \%$ detrital component $(n=1.04)$ and a $10 \%$ mineral component $(n=1.18)$ (Stramski et al., 2001). The fit between the measured $a_{\mathrm{tr}}^{*}$ and that modelled by Mie calculations was very close $\left(R^{2}=0.98\right)$. The following power-law fits were thus determined: $b_{\mathrm{tr}}^{*}=0.648 \lambda^{-0.753}$ and $b_{\mathrm{btr}}^{*}=9.925 e^{-4} \lambda^{-0.0816}$.

The resulting uncertainty to $R_{\mathrm{rs}}$ from the Mie-modeldetermined tripton (back)scattering is likely to be negligible given the very small mean contribution $( \pm 4 \%)$ of tripton particles to $a_{\mathrm{t}}$. Assuming an $a_{\mathrm{p}}(442)$ value of $10 \mathrm{~m}^{-1}$, the corresponding values for $a_{\phi}(442)$ and $a_{\mathrm{tr}}(442)$ would be $9.6 \mathrm{~m}^{-1}$ and $0.4 \mathrm{~m}^{-1}$, respectively. Using $a_{\phi}^{*}(442)=0.035 \mathrm{~m}^{-1}$, a reasonable value for $M$. aeruginosa (Zhang et al., 2012), and $a_{\mathrm{tr}}^{*}(442)$ of $0.037 \mathrm{~m}^{-1}$, the corresponding values for Chl $a$ and TR are $274 \mathrm{mg} \mathrm{m}^{-3}$ and $10 \mathrm{~g} \mathrm{~m}^{-3}$, respectively. Using an approximate value of $b_{\mathrm{b} \phi}^{*}(442)$ of $0.006 \mathrm{~m}^{-1}$ (Zhou et al., 2012) and a value of $b_{\mathrm{btr}}^{*}(442)$ of $6 \times 10^{-4}$ calculated as above, the corresponding values for $b_{\mathrm{b} \phi}(442)$ and $b_{\mathrm{btr}}(442)$ are $1.64 \mathrm{~m}^{-1}$ and $0.006 \mathrm{~m}^{-1}$, respectively. This equates to a contribution of $0.4 \%$ by tripton to $b_{\mathrm{bp}}$. Thus the influence of tripton at these high biomass values is negligible.

The downwelling irradiance was calculated using RADTRAN (Gregg and Carder, 1990) the default atmospheric model for E-S using parameters recorded at each station including the date, latitude, longitude, GMT, wind speed, aerosol optical thickness (AOT, Solar Light Microtops II sun photometer), and cloud cover (\%). Horizontal visibility used by E-S was estimated by vis $=3.9449 /($ AOT500 -0.08498$)$ (Retalis et al., 2010). The air mass type was set to continental. Default values were used for atmospheric pressure $(=29.92$ inches mercury), relative humidity $(=80 \%)$, water vapour $(=1.5)$, and ozone. The vertical profile used was constant with depth, given the shallow optical depth caused by the very high cyanobacterial biomass. E-S was called as a subroutine in Python programming language (V. 2.7.1).
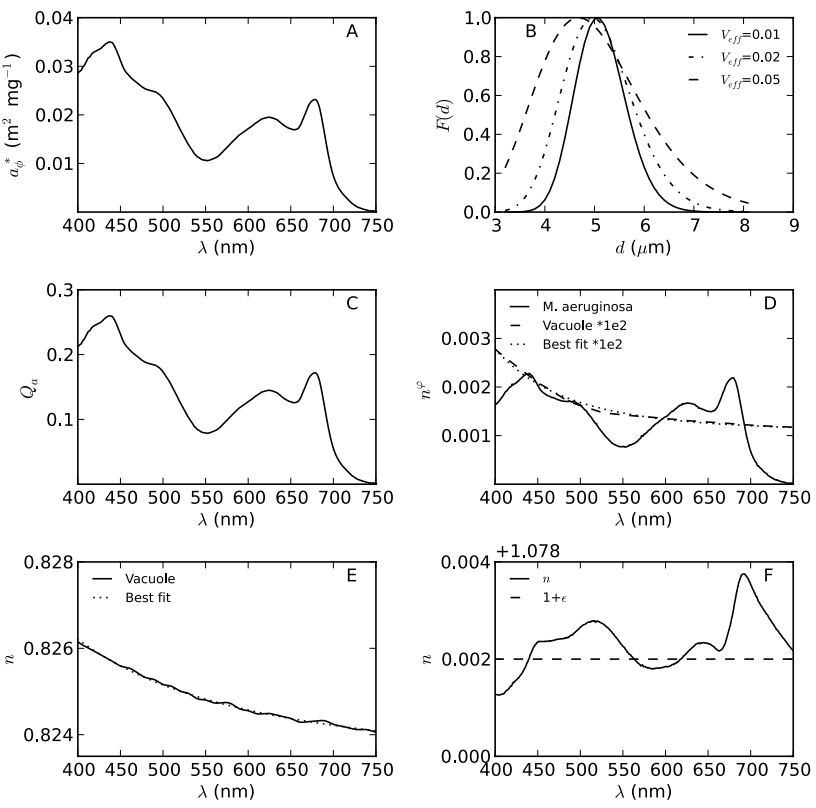

Fig. 1. Optical and size parameters for M. aeruginosa and gas vacuole. (A) Chl $a$-specific absorption, (B) normalised log-normal size distribution function, $F(d)$, for $V_{\mathrm{eff}}=0.01,0.02$, and 0.05 ; (C) experimental absorption efficiency factor; (D) $n^{\prime}$ for $M$. aeruginosa and gas vacuole $\times 1 e^{2}$, showing best-fit line; (E) $n$ for gas vacuole showing best-fit line; and (F) $n$ for $M$. aeruginosa showing $1+\epsilon$ value.

\section{Results and discussion}

\subsection{Complex refractive indices}

Figure 1 shows the data and results of the determination of the complex refractive indices for $M$. aeruginosa and the gas vacuole. The $a_{\phi}^{*}$ value (Fig. 1a) is well within the range presented in the literature for cyanobacteria (e.g. Dupouy et al., 2008), almost identical to that for $M$. aeruginosa determined by Zhang et al. (2012), and slightly higher than values obtained by Dekker (1993) for eutrophic blue-green dominant assemblages. The characteristic absorption maximum of phycocyanin is clearly visible near $620 \mathrm{~nm}$. The $a_{\phi}^{*}$ values used to calculate $m$ did not account for increased apparent absorption that could result from backscatter by gas vacuoles. No attempt was made to correct the measurements for this effect. However, tests showed that variable $a_{\phi}^{*}$ has little effect on the value of $1+\epsilon$ determined by the method. The significance of the variability in $n^{\prime}$ on the IOPs will be investigated further (Sect. 3.4).

The log-normal normalised PSDs are shown in Fig. $1 b$. The effects of varying $V_{\text {eff }}$ is evident on the distribution shapes $\left(r_{\text {eff }}\right.$ is fixed at $\left.2.58 \mu \mathrm{m}\right)$. The narrow distributions are likely to be representative of the spring blooms in Hartbeespoort, and closely resemble those for mono-specific cultures (e.g. Bricaud and Morel, 1986; Ahn et al., 1992). The value chosen for $V_{\text {eff }}$ had a small influence on the 
values determined for $Q_{\mathrm{a}}$ and $n^{\prime}$ but caused more significant changes in $1+\epsilon$ (between 1.078 and 1.081 for $V_{\text {eff }}=0.05$ and 0.01 , respectively). The value for $V_{\text {eff }}$ was set to 0.02 so as to give a spread of smaller and larger cells without incurring a bias towards small cells, as is visible for $V_{\text {eff }}=0.05$.

The experimental $Q_{\mathrm{a}}$ is shown in Fig. 1c, and agrees well with literature-derived values for phytoplankton. $n^{\prime}$ (Fig. 1d) also compares well to the literature values for homogeneous and heterogeneous cells (Ahn et al., 1992; Bricaud and Morel, 1986; Bernard et al., 2009) and has a mean spectral value of $0.0012 i . n$ and $n^{\prime}$ for the vacuole (Fig. 1d, e) have mean spectral values of $2.079 \times 10^{-5} i$ and 0.825 , respectively. The value determined for $n$ in air is 1.10, identical to that estimated by Fuhs (1969) to have the highest probability. These were estimated by power-law functions in further modelling of the IOPs: $n^{\prime}=2.28 e 7 \lambda^{-4.66}+1.08 e^{-5}$ and $n=333 \lambda^{-1.94}+0.82$.

The value of $1+\epsilon$ for $M$. aeruginosa was determined as 1.080 (Fig. 1f). This value was determined at a wavelength of $625 \mathrm{~nm}$, where $n^{\prime}=0.001$. This value represents the mean $n_{m}$ of a Microcystis cell, which includes the cell wall, thylakoids, the cytoplasm, and other refractive cytoplasmic inclusions such as polyphosphate granules. The value is within the range of those presented elsewhere for algal cells (Morel and Bricaud, 1986; Bricaud et al., 1988); however it seems quite high when compared with values used previously for modelling cyanobacteria or M. aeruginosa as a homogeneous cell (e.g. Volten et al., 1998; Zhou et al., 2012). However, the value of 1.04 used by Volten et al. (1998) is an estimate for generic phytoplankton from Morel and Bricaud (1986). A value of 1.036 was determined by Zhou et al. (2012) for cultured M. aeruginosa using similar methods to those presented here; however none of the absorption, size, or attenuation data used to constrain the final choice of $1+\epsilon$ was shown. More comparative values for $1+\epsilon$ between 1.047 and 1.085 are given by natural populations of marine Chlorella (Spinrad and Brown, 1986), which have similar shape (spherical) and size $(d=1.2-6.8 \mu \mathrm{m})$ to $M$. aeruginosa. An $m$ value of $1.085+0.048 i$ was derived for a homogenous cell of marine Chlorella (Quinby-Hunt et al., 1989). Therefore $m=$ $1.080-0.0012 i$ for a homogeneous $M$. aeruginosa cell between 400 and $750 \mathrm{~nm}$ is not outside the range of values determined for algae. The final value for $1+\epsilon$ for the shell layer of a vacuolate cell is determined using $R_{\mathrm{rs}}$ data (see Sect. 2.5).

\subsection{The influence of gas vacuolation on efficiency factors and volume coefficients}

The optical efficiency factors versus the Mie size parameter $\left(\alpha=\pi \mathrm{d} n_{\mathrm{w}} / \lambda\right)$ for a single cell having variable gas vacuole content is shown in Fig. 2. The relative volume occupied by the gas vacuole is $0 \%$, corresponding to an essentially nonvacuolate homogeneous cell; $3 \%$ for an upwardly buoyant cell; 10 and $30 \%$ for an expected vacuole content in a buoy- ant surface bloom; and $50 \%$ for a heavily vacuolate overbuoyant cell. The non-vacuolate cell $\left(V_{\mathrm{g}}=0\right)$ demonstrates the expected interference patterns for $Q_{\mathrm{c}}$ and $Q_{\mathrm{b}}$, tending towards theoretical expectations with increasing size. For cells with increasing vacuole content, there is significant perturbation in the phase, magnitude, and shape of the efficiency factors. This is related to the internal gas vacuole, since the overall pigment content of the cell is constant. For a mean cell in the size range of $M$. aeruginosa, $Q_{\mathrm{c}}$ and $Q_{\mathrm{b}}$ are slightly increased with increasing vacuolation, up to a point where they decrease dramatically with heavy vacuolation $\left(V_{\mathrm{g}}=50 \%\right)$. This is better observed by the spectral efficiency factors for the $M$. aeruginosa population shown in Fig. 3. The upward sloping $Q_{\mathrm{c}}$ and $Q_{\mathrm{b}}$ spectra are probably caused by the relatively high $1+\epsilon$ value (Fig. 3a, b). This value has the greatest influence on the slope and shape of $Q_{\mathrm{c}}$ and $Q_{\mathrm{b}}$ (see Bricaud and Morel, 1986), and its influence is investigated further in Sect. 3.4. The value of $Q_{\mathrm{c}}(510)$ ranges from 2.0 to 2.6, while that of $Q_{\mathrm{b}}(510)$ ranges from 1.85 to 2.45 (Table 2). Therefore according to the two-layered model, gas vacuoles can significantly alter the shape and magnitude of $Q c$ and $Q b$ through a shift in phase of the interference patterns of the efficiency factors (Fig. 2a, b). This finding is in agreement with Dubelaar et al. (1987), who found that gas vacuoles caused decreased overall spectral attenuation (see further analysis in Sect. 3.4). The shift in the position of the red Chl $a$ absorption-induced attenuation feature near $685 \mathrm{~nm}$ towards shorter wavelengths is also visible with increasing vacuolation (Fig. 3a), as observed by Dubelaar et al. (1987). This confirms that gas vacuoles are responsible for this phenomenon.

In accordance with theoretical expectations, $Q_{\mathrm{a}}$ is rather undisturbed by gas vacuolation, except for a very slight decrease with large heavily vacuolate cells (Figs. 2 and 3c). The agreement between the experimental and modelled $Q_{\mathrm{a}}$ is very close using a value of 0.022 for $a_{\text {sol }}^{*}(675)$. However, for gas vacuolation $>50 \%$, there is a small departure from experimental values of $Q_{\mathrm{a}}$ (not shown). This effect is probably caused by a breakdown of the assumption of volume equivalence (Eq. 1) rather than from light shielding or other effects. Therefore a maximum gas vacuole volume of $50 \%$ was used for modelling in order to not violate the volume-equivalence assumption. It is apparent that gas vacuolation has very little implication for absorption according to the two-layered model, and therefore the model does not support a significant light shielding role for gas vacuoles in agreement with Ogawa et al. (1979).

The greatest effect of the gas vacuole is on $Q_{\mathrm{bb}}$ and the backward- and forward-scattering ratios (Figs. 2 and 3d, e, f). $Q_{\mathrm{bb}}(510)$ for a non-vacuolate cell $\left(=7.3 \times 10^{-3}\right)$ falls in the range of algal species modelled with relatively high refractive indices (see Ahn et al., 1992; Bricaud et al., 1988). Vacuolation increases $Q_{\mathrm{bb}}$ markedly in a relatively spectrally invariant and linear fashion and especially for smaller cell sizes in the range of $M$. aeruginosa (Table 2). $Q_{\mathrm{bb}}(510)$ for 
Table 2. Chl $a$-specific volume coefficients $\left(\mathrm{m}^{2} \mathrm{mg}^{-1}\right)$, efficiency factors, and scattering ratios (\%) at $510 \mathrm{~nm}$ for a population of $M$. aeruginosa modelled as two-layered spheres with variable gas vacuole content $(\%)$ for shell layers $1+\epsilon=1.080$ and $1+\epsilon=1.036$.

\begin{tabular}{rcccccccc}
\hline$V_{\mathrm{g}}$ & $c_{\phi}^{*}$ & $b_{\phi}^{*}$ & $b_{\mathrm{b} \phi}^{*} \times 10^{3}$ & $Q_{\mathrm{c}}$ & $Q_{\mathrm{b}}$ & $Q_{\mathrm{bb}}$ & $\tilde{b}_{\mathrm{b} \phi}$ & $\tilde{b}_{\mathrm{f} \phi}$ \\
\hline \multicolumn{8}{c}{$1+\epsilon=1.080$} \\
\hline 0 & 0.27 & 0.25 & 1.0 & 2.00 & 1.85 & 0.0073 & 0.39 & 99.59 \\
3 & 0.28 & 0.26 & 1.2 & 2.09 & 1.94 & 0.0087 & 0.45 & 99.54 \\
10 & 0.32 & 0.30 & 1.4 & 2.34 & 2.18 & 0.0106 & 0.49 & 99.50 \\
30 & 0.35 & 0.33 & 1.8 & 2.60 & 2.44 & 0.0134 & 0.55 & 99.44 \\
50 & 0.35 & 0.33 & 2.1 & 2.60 & 2.45 & 0.0156 & 0.64 & 99.35 \\
\hline \multicolumn{8}{c}{$1+\epsilon=1.036$} \\
\hline 0 & 0.38 & 0.36 & 0.1 & 2.77 & 2.62 & 0.0004 & 0.02 & 99.96 \\
3 & 0.35 & 0.33 & 0.2 & 2.59 & 2.44 & 0.0015 & 0.06 & 99.92 \\
10 & 0.33 & 0.31 & 0.4 & 2.42 & 2.28 & 0.0029 & 0.13 & 99.85 \\
30 & 0.25 & 0.23 & 0.8 & 1.84 & 1.70 & 0.0055 & 0.32 & 99.66 \\
50 & 0.24 & 0.22 & 1.0 & 1.73 & 1.59 & 0.0077 & 0.48 & 99.51 \\
\hline
\end{tabular}
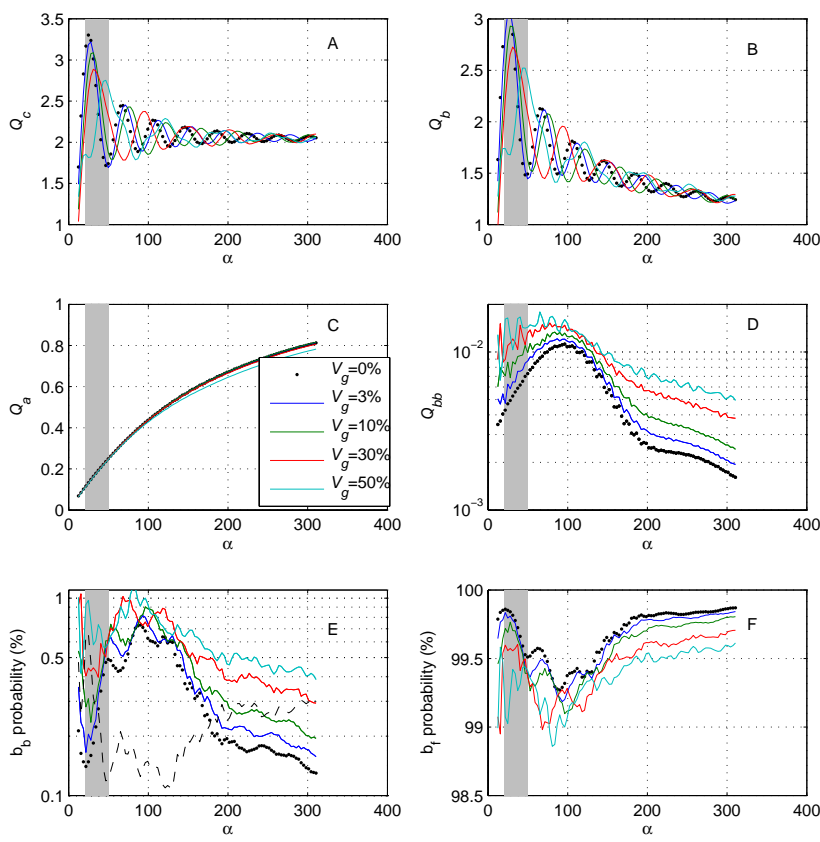

Fig. 2. Optical efficiency factors and the backward- and forwardscattering ratios of $M$. aeruginosa versus the Mie size parameter, $\alpha$, modelled as two-layered spheres with variable gas vacuolation ( $0-50 \%$ cell volume). Plotted for cell diameters from 1 to $50 \mu \mathrm{m}$ at $\lambda=675 \mathrm{~nm}$. The shading indicates the size range applicable to $M$. aeruginosa. The dotted line in $(\mathbf{E})$ is the ratio of backscattering probability where $V_{\mathrm{g}}=50 \%$ to that where $V_{\mathrm{g}}=0 \% \times 10^{-1}$.

a heavily vacuolate cell $(=0.0156)$ is twice that of its homogeneous equivalent. $\tilde{b_{\mathrm{b}}}$ may be up to five times larger in a heavily vacuolate cell than for a homogeneous equivalent in the size range of $M$. aeruginosa (Fig. 2e). This effect is associated with decreased $\tilde{b_{\mathrm{f}}}$ by up to $0.5 \%$ (Fig. $2 \mathrm{f}$ ), as was observed experimentally by Dubelaar et al. (1987). How- ever, the spectral slope of $\tilde{b_{\mathrm{b}}}$ indicates enhanced backscattering with higher vacuole content towards the red relative to the blue (Fig. 3e). These curves closely resemble those determined experimentally (e.g. Zhou et al., 2012). The opposite is observed for forward-scattering probability (Fig. 3f). Therefore the following can be said in relation to the effect of gas vacuoles on backscattering: firstly it appears that gas vacuolation has large implications for small cells, of which $M$. aeruginosa is an example; secondly, $Q_{\mathrm{bb}}$ increases roughly linearly with increasing vacuole content; and lastly, $\tilde{b_{\mathrm{b}}}$ seems to be enhanced in the red relative to the blue for cells with a high gas vacuole content.

The Chl $a$-specific volume coefficients for variable gas vacuolation are shown in Fig. $4 \mathrm{a}-\mathrm{d}$. The shapes of the attenuation and scattering spectra are identical to the efficiency factors in Fig. 3. The range of values for $b_{\phi}^{*}(510)$ from 0.25 to $0.33 \mathrm{~m}^{2} \mathrm{mg}^{-1}$ are towards the upper range of values observed for cyanophyta and phytoplankton in modelling studies (Morel and Bricaud, 1986; Bricaud et al., 1988). The downward-sloping attenuation curves for $V_{\mathrm{g}}=50 \%$ resemble those previously measured for $M$. aeruginosa (Dubelaar et al., 1987). The modelled Chl $a$-specific absorption is almost identical to the measured value (see Fig. 1). $b_{\mathrm{b} \phi}^{*}(510)$ is $1.0 \times 10^{-3} \mathrm{~m}^{2} \mathrm{mg}^{-1}$ for a non-vacuolate cell, and $2.1 \times 10^{-3} \mathrm{~m}^{2} \mathrm{mg}^{-1}$ for a heavily vacuolate cell. This amounts to a two-fold increase in $b_{\mathrm{b} \phi}^{*}$ due to the presence of the gas vacuole. The values are within experimental values for phytoplankton (e.g. Whitmire et al., 2010) but are lower than those observed for $M$. aeruginosa by Zhou et al. (2012) $\left(=5.727 \times 10^{-3} \mathrm{~m}^{2} \mathrm{mg}^{-1}\right)$ and the vacuolate marine cyanophyte Trichodesmium $\left(=11 \times 10^{-3} \mathrm{~m}^{2} \mathrm{mg}^{-1}\right)$ (Dupouy et al., 2008). $b_{\mathrm{b} \phi}^{*}$ is slightly negatively sloped but becomes more positively sloped towards the red $>700 \mathrm{~nm}$ with increasing vacuolation. Previous measurements of $b_{\mathrm{b} \phi}^{*}$ for $M$. aeruginosa show a downward-sloping spectral shape 

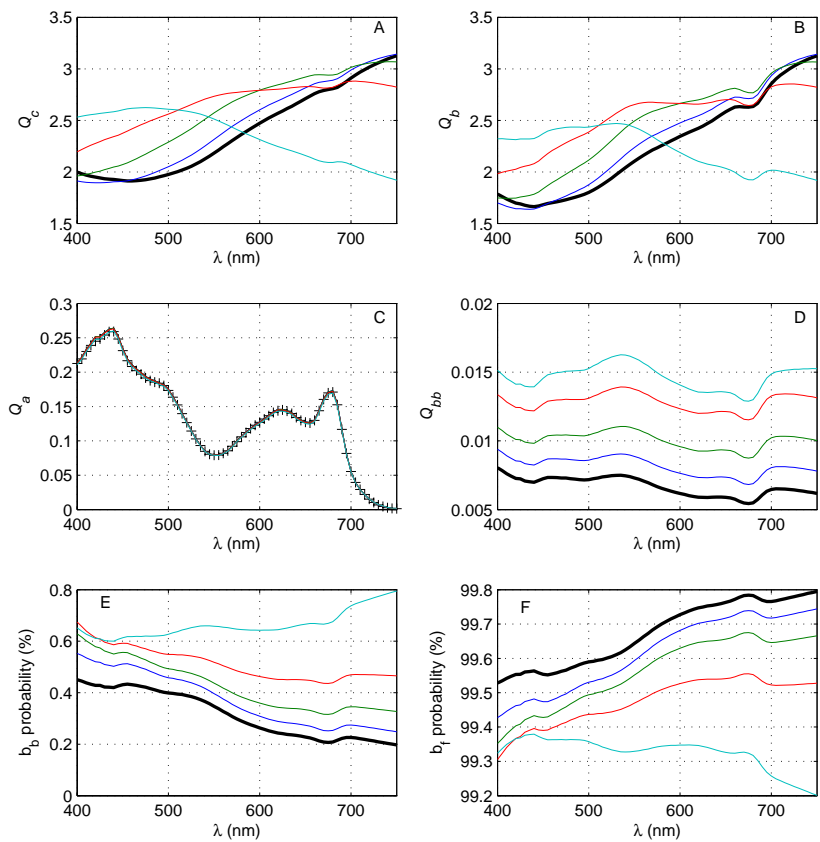

Fig. 3. Optical efficiency factors and forward- and backwardscattering ratios of a population of $M$. aeruginosa modelled as twolayered spheres with variable gas vacuolation (0-50\% cell volume). Legend is the same as Fig. 2. The measured absorption efficiency factor is drawn for comparison in $\mathrm{C}(+)$.

(Zhou et al., 2012). The change in $n^{\prime}$ and $n$ due to vacuolation for the shell chromatoplasm layer is shown in Fig. 4e and $\mathrm{f}$. The space occupied by the gas vacuole causes the absorbing material to be concentrated, thereby increasing the value of $n^{\prime}$ which leads to associated changes in $\Delta n$. This assumes that the size of the cell remains unchanged by vesicle synthesis.

\subsection{The influence of gas vacuolation on the VSF}

There have been limited attempts to measure and model the scattering phase function (light-scattering matrix) of $M$. aeruginosa both with and without gas vacuoles. Schreurs (1996) performed measurements presented in Volten et al. (1998) at $633 \mathrm{~nm}$ using an helium-neon laser to measure the VSF of vacuolate and pressurised (non-vacuolate) M. aeruginosa and another vacuolate Microcystis species. The presence of gas vacuoles was observed to cause unusual features in the VSF, specifically an increase in magnitude between 20 and $70^{\circ}$ and a decline towards the forward direction $<40^{\circ}$. Similar to other studies citing the importance of intracellular structure on the scattering matrix (e.g. QuinbyHunt et al., 1989; Witkowski et al., 1998; Svensen et al., 2007), these features have been speculatively attributed to gas vacuoles. The same studies used a population of homogeneous spheres using Lorenz-Mie theory to attempt to fit the measurements $\left(n=1.04, n^{\prime}=0.000\right)$. However, the homoge-
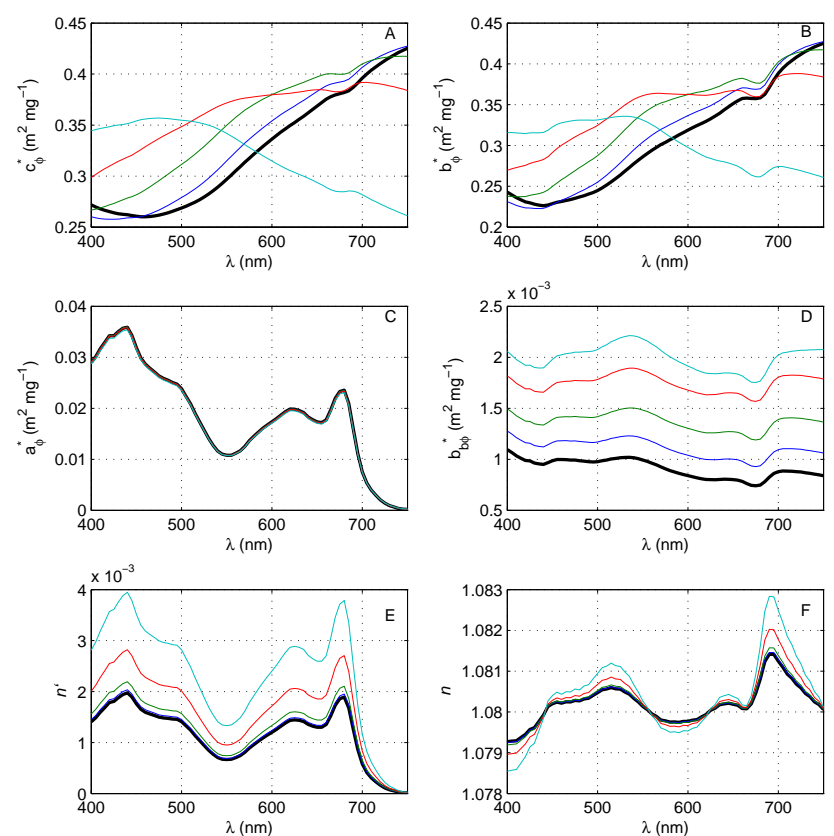

Fig. 4. Chl $a$-specific volume coefficients for a population of $M$. aeruginosa modelled as two-layered spheres with variable gas vacuolation (A-D). Legend same as Fig. 2. The influence of gas vacuolation on the $n^{\prime}$ and $n$ of the shell layer are also shown $(\mathbf{E}, \mathbf{F})$.

neous sphere model produced poor comparisons with measurements of both vacuolate and non-vacuolate cells. The flattening towards forward angle was only reproduced with a cell of significantly reduced $n=0.4$ (Schreurs, 1996). The influence that gas vacuoles might have on the VSF in the extreme forward and backward directions remains unknown for the present time. Although recently developed instruments have the capability to measure the VSF between 0.6 and $177^{\circ}$ (e.g. Zhang et al., 2002), no such measurements on vacuolate and non-vacuolate cells appear to have yet been made.

Figure 5a-d show the VSFs at four wavelengths. Three features attributable to the gas vacuole are immediately apparent: an enlargement between 20 and $70^{\circ}$, a flattening towards the forward direction $<45^{\circ}$, and a steady enhancement and flattening of the VSF in the backward direction $>90^{\circ}$ for increasing vacuole content. The results are compared to those of Volten et al. (1998) in Fig. 5e and normalised to the San Diego Harbor VSF at $90^{\circ}$ (Petzold, 1972). The twolayer model for a vacuolate cell containing $V_{\mathrm{g}}=10 \%$ accurately reproduces the enhanced scattering between 20 and $70^{\circ}$, as well as the flattening in the forward direction $<45^{\circ}$ observed for vacuolate cells. The fit between the modelled homogeneous cell and the measured non-vacuolate cell is also good in the forward direction $\left(<90^{\circ}\right)$. The enhancement in the backward direction from vacuoles is not observable in the measurements of Volten et al. (1998), and the magnitude of the measured VSF in the backward direction is substantially greater than that from the model. This is most likely 

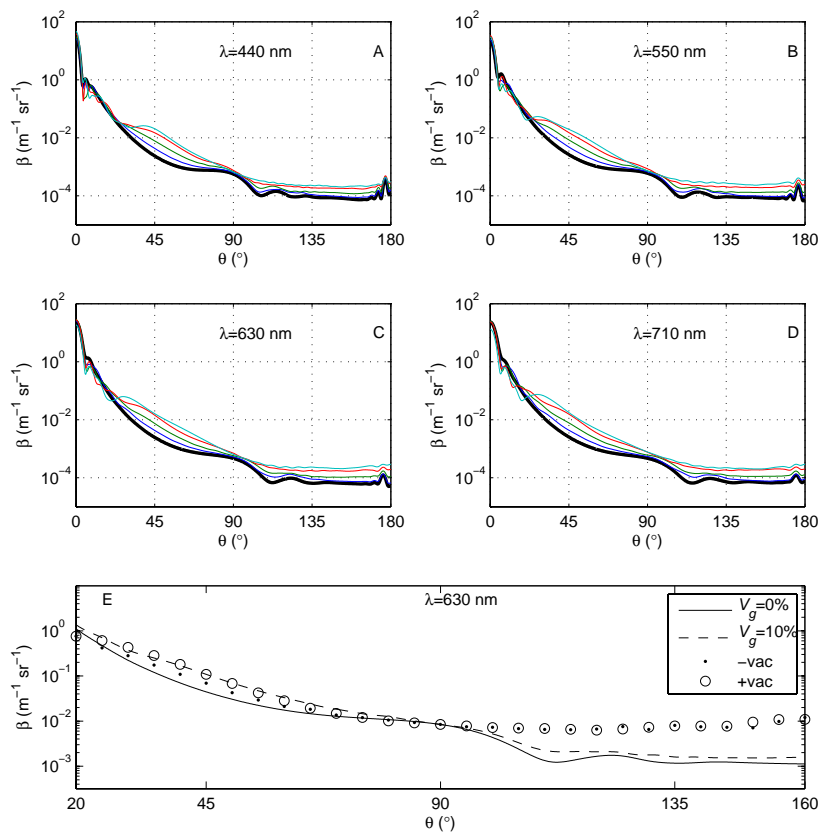

Fig. 5. Volume scattering functions for a population of $M$. aeruginosa at various wavelengths modelled as two-layered spheres with variable gas vacuolation ( $0-50 \%$ cell volume). Legend same as Fig. 2. (E) shows comparison of these results with measurements of vacuolate (+vac) and non-vacuolate ( $-\mathrm{vac})$ M. aeruginosa made by Volten et al. (1998) at $633 \mathrm{~nm}$ (scaled to San Diego Harbor measurements of Petzold (1972) at $\left.90^{\circ}\right)$.

caused by the assumption of sphericity, since the VSF in the backward direction is heavily influenced by non-sphericity (Clavano et al., 2007). Tests varying some of the model's parameters and using those presented in Volten et al. (1998) $\left(n=1.04, n^{\prime}=0.000, V_{\text {eff }}=0.92, R_{\text {eff }}=6.83\right)$ did not produce an improved fit. Nevertheless, the two-layered vacuole model accurately reproduces observations of the normalised VSF in the forward direction.

\subsection{Influence of the choice of $1+\epsilon$ and $c_{i}$ on the IOPs}

The value for $1+\epsilon=1.036$ chosen by Zhou et al. (2012) was also used to calculate the IOPs for comparison with Sect. 3.1 (Fig. 6, Table 2). The resulting attenuation spectra compare more closely with the findings of Dubelaar et al. (1987) (Fig. 6a): the curves slope downwards towards the red, lower vacuole content results in gradually increased attenuation, and the shift of the attenuation peak caused by the absorption maximum of $\mathrm{Chl} a$ towards shorter wavelengths with increasing vacuolation is clearly observed $(681 \mathrm{~nm}$ for $V_{\mathrm{g}}=50 \%, 685 \mathrm{~nm}$ for $V_{\mathrm{g}}=0 \%$ ). Therefore, gas vacuolation is likely the cause of these changes in attenuation. Spectral scattering is also decreased with increasing vacuolation in a manner similar to attenuation (absorption was constant) (Fig. 6b). The lower $1+\epsilon$ value results in substantially lower backscattering relative to the higher refractive index value
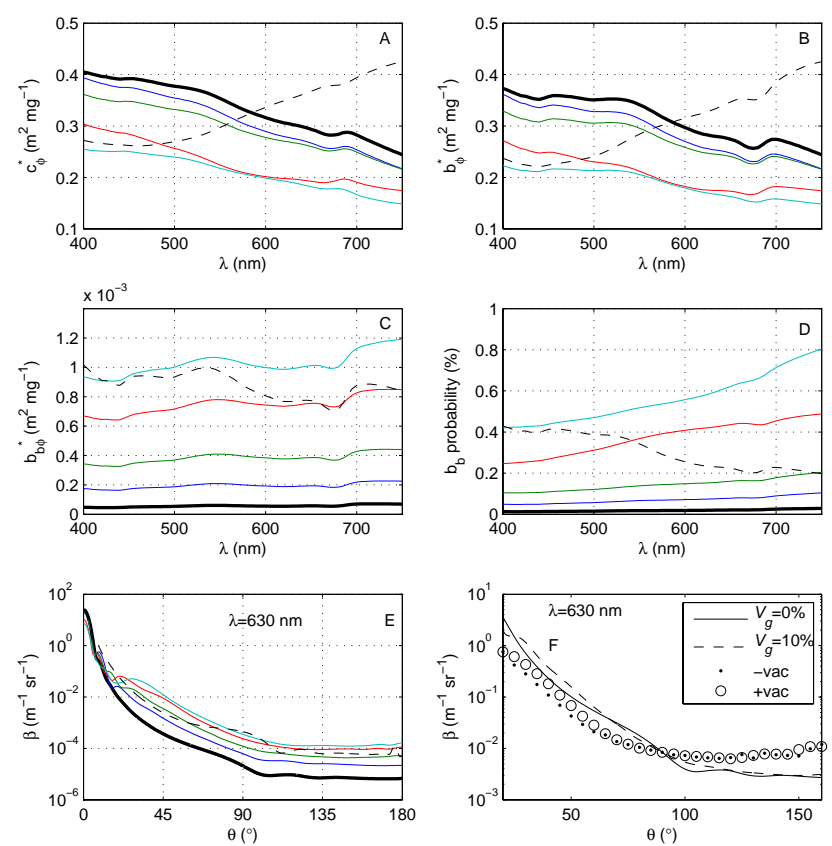

Fig. 6. Chl $a$-specific IOPs and VSFs for a population of M. aeruginosa modelled as two-layered spheres with variable gas vacuolation (0-50\% cell volume) and $1+\epsilon=1.036$. The dotted line in $(\mathbf{A}-\mathbf{E})$ is for a cell with $V_{\mathrm{g}}=0 \%$ and $1+\epsilon=1.080$. Legend same as Fig. 2 . (F) shows comparison with measurements of Volten et al. (1998) (see Fig. 5 for details).

(Fig. 6c, d). The heavily vacuolate cell $\left(V_{\mathrm{g}}=50 \%\right)$ scatters approximately the same as a non-vacuolate cell with the higher refractive index. The lower refractive index cell responds in much the same way as the cell with the higher refractive index to vacuolation, with backscatter increasing in a roughly linear manner for increasing percentage vacuolation. The probability of backscatter for the lower refractive index cell is, however, more sloped, indicating a bias for light scatter in the red rather than in the blue. The VSF for the lower refractive index cell is generally smaller than for the higher refractive index cell, but less sloped in the backward direction (Fig. 6e, f). The comparison with the measured scattering function of Volten et al. (1998) is poorer in the forward direction $(<\pi / 2)$ but slightly improved in the backward direction $(>\pi / 2)$. The distinctive features causing an enhancement and flattening in the VSF at forward angles is reproduced by the model.

The lower and higher refractive index cells respond in very similar ways to increasing gas vacuolation and reproduce experimental observations in $c$ and $b$, as well as in the VSF. The $1+\epsilon$ value controls both the shape of $c$ and $b$ and the magnitude of $b_{\mathrm{b}}$; therefore it is one of the primary causal variables, along with the vacuole itself, influencing the IOPs. Although the shape of spectral attenuation may be used to constrain the choice of $1+\epsilon$ (Bricaud and Morel, 1986), favouring a lower $1+\epsilon$ value, the higher $1+\epsilon$ value agrees better with 
Table 3. Effect of variable $c_{\mathrm{i}}$ on $m$ and IOPs $(510 \mathrm{~nm})$ of a population of vacuolate cells $\left(V_{\mathrm{g}}=50 \%\right)$.

\begin{tabular}{lrrr}
\hline$c_{\mathrm{i}}\left(\mathrm{kg} \mathrm{m}^{-3}\right)$ & 2.096 & 3.16 & 4.525 \\
\hline $\bar{Q}_{\mathrm{a}}(675)$ & 0.145 & 0.219 & 0.313 \\
$n^{\prime}(675)$ & 0.0017 & 0.0026 & 0.0041 \\
$1+\epsilon$ & 1.0801 & 1.0801 & 1.0805 \\
$Q_{\mathrm{b}}$ & 2.45 & 2.36 & 2.27 \\
$Q_{\mathrm{bb}}$ & 0.016 & 0.015 & 0.014 \\
$b_{\phi}^{*}\left(\mathrm{~m}^{2} \mathrm{mg}^{-1}\right)$ & 0.33 & 0.21 & 0.14 \\
$b_{\mathrm{b} \phi}^{*}\left(\mathrm{~m}^{2} \mathrm{mg}^{-1}\right)$ & 0.0021 & 0.0013 & 0.0008 \\
$\tilde{b}_{\mathrm{b} \phi}\left(\mathrm{m}^{2} \mathrm{mg}^{-1}\right)$ & 0.0064 & 0.0062 & 0.0060 \\
\hline
\end{tabular}

measurements of the VSF and IOPs (Table 3). The final value for $1+\epsilon$, however, is determined in Sect. 3.5 below.

The influence of $c_{\mathrm{i}}$ on the IOPs was also investigated using the values of $2.1 \mathrm{~kg} \mathrm{~m}^{-3}, 3.2 \mathrm{~kg} \mathrm{~m}^{-3}$, and $4.5 \mathrm{~kg} \mathrm{~m}^{-3}$ from Zhou et al. (2012), Agusti and Phlips (1992), and Reynolds et al. (1981), respectively (Table 3 ). The $c_{\mathrm{i}}$ value is directly linked to $Q_{\mathrm{a}}$ and causes changes in the values of $n^{\prime}$ and $n$ due to the method used to determine $m$ (Sect. 2.2). Higher $c_{\mathrm{i}}$ values give higher values for $Q_{\mathrm{a}}$ and therefore $n^{\prime}$; however the value determined for $n$ is relatively unchanged (Table 3). The variable $Q_{\mathrm{a}}$ and $n^{\prime}$ values result in changes in the (back)scattering efficiencies and in the Chl $a$-specific IOPs produced by the two-layer model: higher $c_{\mathrm{i}}$ values are associated with lower $Q_{\mathrm{b}}$ and $Q_{\mathrm{bb}}$ values, and much smaller values for $b_{\phi}^{*}$ and $b_{\mathrm{b} \phi}^{*}$ (Table 3 ). The changes in the Chl $a$ specific IOPs are primarily caused by normalising the PSD by chlorophyll. Therefore $c_{\mathrm{i}}$ has a large controlling influence on the two-layered model. The choice of $c_{\mathrm{i}}$ in this case was determined by the closeness to literature values: the lowest $c_{\mathrm{i}}$ value $=2.1 \mathrm{~kg} \mathrm{~m}^{-3}$ most closely reproduced Zhou et al.'s (2012) $Q_{\mathrm{b}}$ and $Q_{\mathrm{bb}}$ values, which were 2.26 and 0.02 , respectively. A second reason for choosing the low $c_{\mathrm{i}}$ value is that higher $c_{\mathrm{i}}$ values were unable to reproduce the high values for $b_{\mathrm{b} \phi}^{*}$ observed in buoyant $M$. aeruginosa blooms. The higher $c_{\mathrm{i}}$ values had a dampening effect on scattering probably due to the concentration of absorbing material in the shell layer. For these reasons the lower $c_{\mathrm{i}}$ value was used.

\subsection{Variable chromatoplasm $1+\epsilon$ values determined using $\boldsymbol{R}_{\mathrm{rs}}$}

The measured and modelled $R_{\mathrm{rs}}$ spectra estimated using variable values of $1+\epsilon$ for the chromatoplasm are shown in Fig. 7a and b. The spectral shapes of $R_{\mathrm{rs}}$ produced by the bio-optical model and E-S are in good agreement with those measured. The difference between 400 and $750 \mathrm{~nm}$ is on average better than $0.005 \mathrm{sr}^{-1}$, which is likely to be satisfactory given the high $R_{\mathrm{rs}}$ values (Fig. 7c). There is a good spread of over- and underestimates for $R_{\mathrm{rs}}$, with no apparent consistent bias for wavelengths $>700 \mathrm{~nm}$ (Fig. 7d). The wavelength-
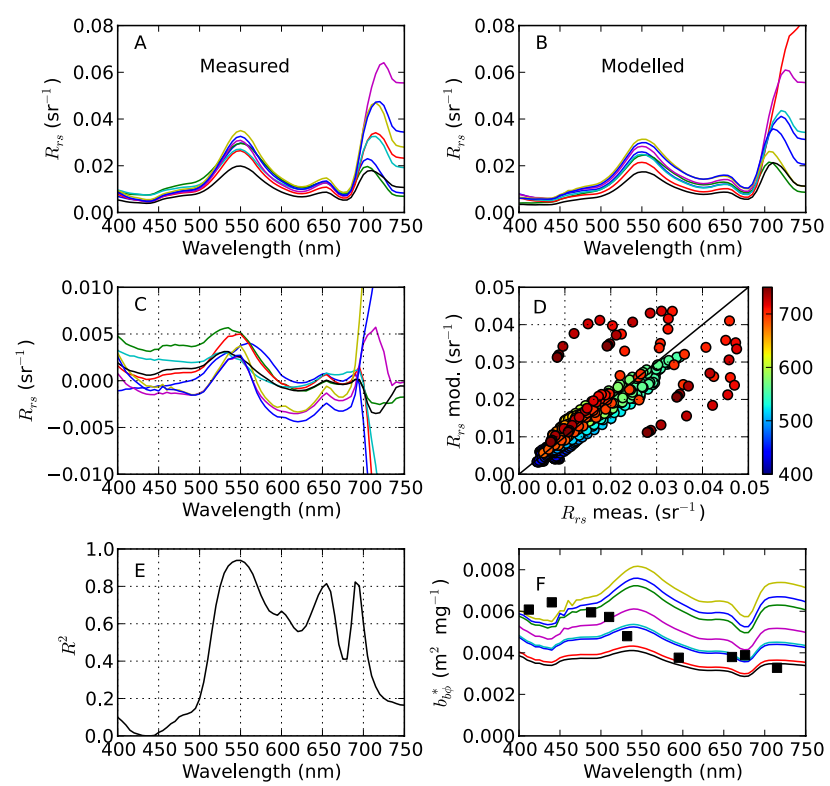

Fig. 7. Tuning of the two-layered sphere model using measured $R_{\text {rs }}$ (A) Measured and (B) modelled $R_{\mathrm{rs}}$ and (C) the difference between the measured and modelled $R_{\mathrm{rs}}$. (D) Scatterplot of measured and modelled reflectance coloured by wavelength. (E) Wavelengthspecific $R^{2}$ between measured and modelled $R_{\mathrm{rs}}(N=8)$. (F) $b_{\mathrm{b} \phi}^{*}$ corresponding to various shell layer $1+\epsilon$ values determined by fitting the measured and modelled $R_{\mathrm{rs}}$, and that measured by Zhou et al. (2012) (squares). Colours in (A), (B),(C) and (F) represent different samples.

specific coefficient of determination (Fig. 7e) has troughs in the regions corresponding to the fluorescence bands of phycobilipigments (550 to $650 \mathrm{~nm}$ ) and Chl $a$ (near $685 \mathrm{~nm}$ ). This is expected since the model does not account for fluorescence effects. The poor performance $<500$ and $<700 \mathrm{~nm}$ is most likely related to uncertainties in $b_{\mathrm{b} \phi}^{*}$ towards the blue and near infrared (NIR), respectively. The small sample size ( $n=8$ ) must also be taken to account in the $R^{2}$ calculations. However, the correlation is sufficiently good in the regions 500 to $700 \mathrm{~nm}$ given that errors in $R_{\mathrm{rs}}$ determined in situ may be $>10 \%$ depending on the wavelength and measurement conditions (Doxaran et al., 2004).

The mean value of $b_{\mathrm{b} \phi}^{*}(510)$ is $5.48 \times 10^{-3} \mathrm{~m}^{2} \mathrm{mg}^{-1}$ with a range of 3.89 to $7.19 \times 10^{-3} \mathrm{~m}^{2} \mathrm{mg}^{-1}$. These values agree closely with that determined for cultured vacuolate $M$. aeruginosa by Zhou et al. (2012) of $5.7 \times 10^{-3} \mathrm{~m}^{2} \mathrm{mg}^{-1}$ (Fig. 7f). They are also within the range of values measured for $\mathrm{Mi}$ crocystis-dominated assemblages in Lake Rosarito, Spain (=3.6 to $5.3 \times 10^{-3} \mathrm{~m}^{2} \mathrm{mg}^{-1}$ at $412 \mathrm{~nm}$ ) (A. Ruiz-Verdu, personal communication, 2013). The $b_{\mathrm{bp}}$ profiles for Hartbeespoort measured in situ are shown in (Fig. 8a, b). The estimated Chl $a$-specific particulate backscattering at $z=0.8 \mathrm{~m}$ and $440 \mathrm{~nm}$ ranged from 0.37 to $1.5 \times 10^{-3} \mathrm{~m}^{2} \mathrm{mg}^{-1}$, and at $700 \mathrm{~nm}$ from 1.9 to $7.8 \times 10^{-3} \mathrm{~m}^{2} \mathrm{mg}^{-1}$. This is in the same 

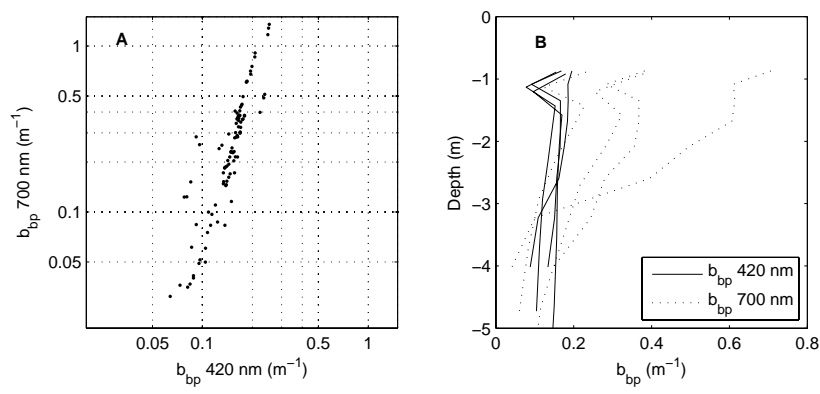

Fig. 8. (A) $b_{\mathrm{bp}}(700)$ vs. $b_{\mathrm{bp}}(420)$ from 11 profiles. Note exponential relationship with log-scaled axes. (B) Five selected depth profiles with minimum depth of $0.8 \mathrm{~m}$. Note that $b_{\mathrm{bp}}(420)>b_{\mathrm{bp}}(700)$ at depth.

order of magnitude as those estimated from $R_{\mathrm{rs}}$. The $b_{\mathrm{bp}}^{*}$ values are likely underestimates since $\mathrm{Chl} a$ was measured at the surface and the blooms were floating. There is some disagreement in the spectral shape between Zhou et al. (2012) (Chl $a$ approximately $5 \mathrm{mg} \mathrm{m}^{-3}$ ) and the two-layered sphere estimates (Fig. 7f). Interestingly, $b_{\mathrm{bp}}$ is positively sloped towards the red near the surface and negatively sloped at depth (Fig. 8b). Therefore there is some evidence for an upwardsloping $b_{\mathrm{b} \phi}$ for $M$. aeruginosa, in contrast to those of Zhou et al. (2012), which are downward-sloping. The explanation for the depth-variable slope is not known, but seems to be related to biomass; if biomass affects the spectral slope, then this finding has has important implications for $b_{\mathrm{bp}}$ measured using cultures. In summary, the $b_{\mathrm{b} \phi}^{*}$ values are typically larger or in the upper range of those determined experimentally for cultured algae (e.g. Whitmire et al., 2010; Vaillancourt, 2004), and are in good agreement with the limited measurements made on vacuolate $M$. aeruginosa.

The modelled $R_{\mathrm{rs}}$ spectra correspond to chromatoplasm $1+\epsilon$ values varying between 1.104 and 1.138 with a mean value of 1.12 . The $1+\epsilon$ values estimated using $R_{\mathrm{rs}}$ are likely to be justified for the following reasons: the overwhelming optical dominance of phytoplankton relative to other water components, meaning that from an optical perspective, the measurements were effectively performed on "cultures"; aside from $V_{\mathrm{g}}$ and some small uncertainty related to the estimated PSD, the primary factor controlling phytoplankton backscatter is the chromatoplasm $1+\epsilon$ value, which was the only variable parameter used to determine appropriate values for $R_{\mathrm{rs}}$; the range of $1+\epsilon$ values fall in the expected range of eukaryotic chloroplasts of 1.09 to 1.19 , mean of 1.14 (Bernard et al., 2009), and result in an overall homogeneous $n$ of 0.97 by volume equivalence; and finally, the resulting values determined for $b_{\mathrm{b} \phi}^{*}$ are in close agreement with measurements made on vacuolate cultures and natural blooms of M. aeruginosa.

Furthermore, the chromatoplasm $1+\epsilon$ values accord with previous two-layered modelling efforts: Quinby-Hunt et al. (1989) used a shell layer $n=1.13$ and core $n=1.08$ to best
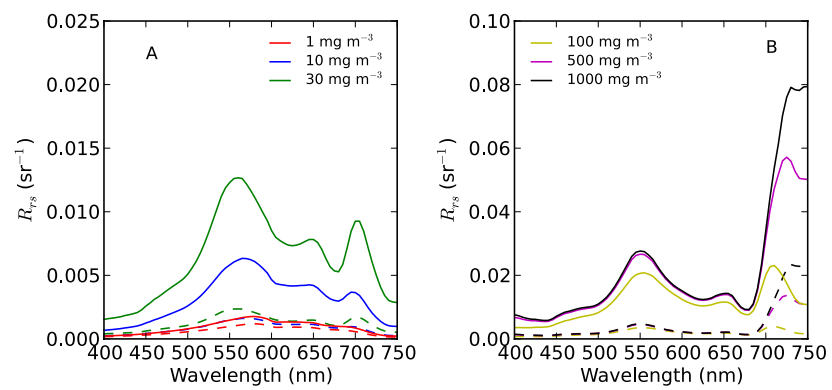

Fig. 9. $R_{\mathrm{rs}}$ modelled at various concentrations of $\mathrm{Chl} a$ showing the difference between vacuolate (solid lines) and non-vacuolate (dotted lines) populations of $M$. aeruginosa. Vacuolate cells were modelled with shell $1+\epsilon$ of 1.12 and $V_{\mathrm{g}}=50 \%$. Non-vacuolate cells were homogeneous cells with $1+\epsilon$ of 1.080 . The values for $a_{\mathrm{tr}}(440)$ and $a_{\mathrm{g}}(440)$ were constant at 0.5 and $1.5 \mathrm{~m}^{-1}$, respectively. For more details, see the text.

reproduced the scattering matrix of Chlorella, a species with similar morphology to $M$. aeruginosa, and the typical $1+\epsilon$ value for a shell layer proxy for the cell wall is 1.2 (e.g. Svensen et al., 2007). Given these considerations, the resulting $1+\epsilon$ values as determined by $R_{\mathrm{rs}}$ are likely to be appropriate, although assumptions are made regarding several components affecting the $R_{\mathrm{rs}}$ (e.g. the VSF for the tripton particles estimated using a Mie model).

$Q$ factors and Chl $a$-specific volume coefficients determined using the two-layered sphere with the mean chromatoplasm $1+\epsilon$ value of 1.12 are shown in comparison to those measured by Zhou et al. (2012) in Table 4. The values for $Q_{\mathrm{b}}(510)$ and $Q_{\mathrm{bb}}(510)$ compare well, but measured $b_{\phi}^{*}$ values are substantially higher than those from the twolayered sphere. It appears that the two-layered model has a lower total scattering due to the slightly lower value of $Q_{\mathrm{b}}$. The backscattering probability is also elevated for the twolayered model, although $b_{\mathrm{b} \phi}^{*}(510)$ is very close.

In comparison with eukaryotic species $Q_{\mathrm{bb}}$ is in the upper range of values measured on cultures: from 0.0018 to 0.064 at $510 \mathrm{~nm}$ (Zhou et al., 2012; Vaillancourt, 2004) and from 0.006 to 0.061 at $442 \mathrm{~nm}$ (Whitmire et al., 2010). Surprisingly, the largest of $Q_{\mathrm{bb}}$ values are from large dinoflagellates containing high intracellular carbon concentrations and unusual chromosome morphology and internal structures. This internal structure is used as an explanation for the higherthan-expected $Q_{\mathrm{bb}}$. Using similar reasoning, intracellular gas vacuoles in $M$. aeruginosa are responsible for the high $Q_{\mathrm{bb}}$ values. 
Table 4. Optical efficiency factors and Chl $a$-specific volume coefficients $\left(\mathrm{m}^{2} \mathrm{mg}^{-1}\right)$ at $510 \mathrm{~nm}$ for a population of $M$. aeruginos $a$ modelled as a population of two-layered spheres with shell layer $1+\epsilon=1.12$ and $V_{\mathrm{g}}=50 \%$.

\begin{tabular}{lrrrrrrr}
\hline & $Q_{\mathrm{c}}$ & $Q_{\mathrm{b}}$ & $Q_{\mathrm{bb}}$ & $c_{\phi}^{*}$ & $b_{\phi}^{*}$ & $b_{b \phi}^{*} \times 10^{3}$ & $\tilde{b}_{\mathrm{bb}}(\%)$ \\
\hline Two-layered spheres & 2.35 & 2.20 & 0.040 & 0.321 & 0.30 & 5.5 & 1.8 \\
Zhou et al. (2012) & - & 2.26 & 0.020 & - & 0.6326 & 5.7 & 0.91 \\
\hline
\end{tabular}
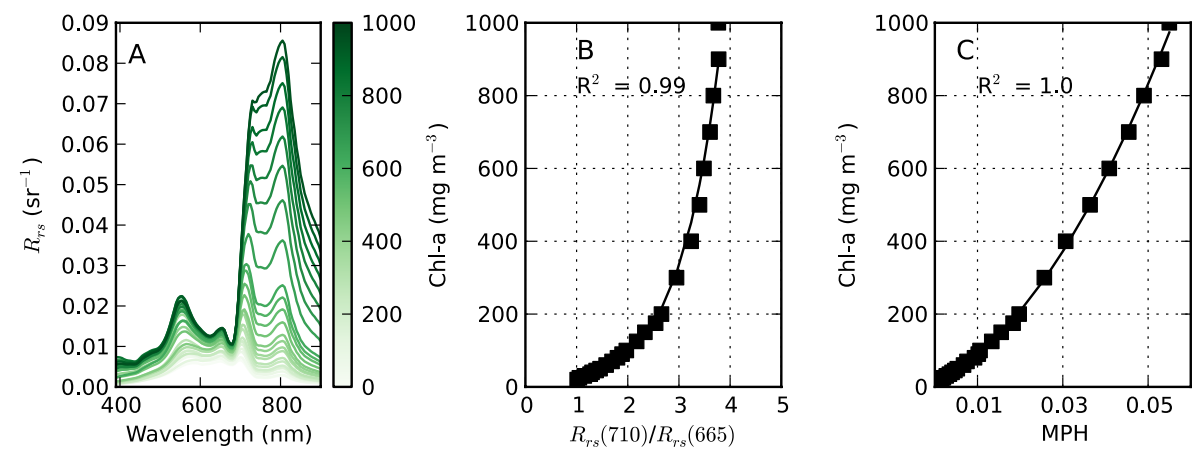

Fig. 10. (A) $R_{\mathrm{rs}}$ simulated for $\mathrm{Chl} a$ between 20 and $1000 \mathrm{mg} \mathrm{m}^{-3}$ for a vacuolate $M$. aeruginosa population with random perturbations in tripton concentration and $a_{\mathrm{g}}(440)$. Empirical relationships between $\mathrm{Chl} a$ and the $710: 665$ band ratio (B) and between Chl $a$ and the maximum peak height (MPH) variable (C) showing the best fit lines.

\section{Applications}

\subsection{Influence of gas vacuoles on reflectance}

The large magnitude of $R_{\mathrm{rs}}$ and scattering in buoyant surface cyanobacterial blooms has been tentatively attributed to the presence of gas vacuoles (e.g. Ganf et al., 1989). The potential effect that intracellular gas vacuoles might have on the magnitude of $R_{\mathrm{rs}}$ was investigated through simulations for populations of vacuolate versus non-vacuolate cells. Vacuolate cells were modelled with a chromatoplasm $1+\epsilon$ value of 1.12 and $V_{\mathrm{g}}=50 \%$, while homogeneous cells had $1+\epsilon$ of 1.08 , inside the plausible range for phytoplankton cells (Aas, 1996). In the simulations, $a_{\mathrm{tr}}(440)$ and $a_{\mathrm{g}}(440)$ were set to constant values typical of Hartbeespoort of 0.5 and $1.5 \mathrm{~m}^{-1}$, respectively. E-S was run using a solar zenith angle of $30^{\circ}$, a wind speed of $2 \mathrm{~m} \mathrm{~s}^{-1}$, and default atmospheric parameters.

$R_{\mathrm{rs}}$ for vacuolate and non-vacuolate $M$. aeruginosa populations was computed for Chl $a$ between 1 and $1000 \mathrm{mg} \mathrm{m}^{-3}$, a plausible range for Hartbeespoort (Fig. 9a, b). The magnitude of $R_{\mathrm{rs}}$ for the vacuolate population is in the range observed in buoyant surface cyanobacterial blooms and those measured in this study (see Wang et al., 2010; Matthews et al., 2010; Randolph et al., 2008; Zimba and Gitelson, 2006). A large difference in the magnitude of $R_{\mathrm{rs}}$ between the vacuolate and non-vacuolate populations is apparent, which becomes increasingly pronounced as the concentration of Chl $a$ increases. This effect is due solely to the increase in $b_{\mathrm{b} \phi}^{*}$ associated with vacuolate cells. The peak near $710 \mathrm{~nm}$ becomes apparent around $\mathrm{Chl} a=30 \mathrm{mg} \mathrm{m}^{-3}$ (note the model does not include fluorescence effects at $685 \mathrm{~nm}$ ). For Chl $a>500 \mathrm{mg} \mathrm{m}^{-3}, R_{\mathrm{rs}}$ is enlarged significantly towards the NIR $(>700 \mathrm{~nm})$. This is typical of surface $M$. aeruginosa blooms, allowing them to be distinguished from other species of algae, e.g. dinoflagellates (Matthews et al., 2012). Therefore algorithms for detection/discrimination of vacuolate cyanophyte blooms might be targeted at the enlarged signal at these wavelengths. The results demonstrate the large influence variable phytoplankton backscatter resulting from gas vacuoles may have on the magnitude of $R_{\mathrm{rs}}$ and provide an explanation for the high values observed in hypertrophic cyanobacteria-dominant waters.

\subsection{Sensitivity study of existing empirical models for estimating Chl $a$}

While semi-analytical algorithms based on bio-optical models and solved using a variety of optimisation procedures are often used for deriving water constituents, forward-modelled $R_{\mathrm{rs}}$ from bio-optical models also allow empirical relationships for water constituents to be validated (e.g. Matthews, 2011; Dekker et al., 2001). In this example, the sensitivity of existing empirical relationships between $\mathrm{Chl} a$ and a $710: 665 \mathrm{~nm}$ band ratio and a baseline subtraction algorithm called the maximum peak height (MPH) algorithm (Matthews et al., 2012) were tested using simulated $R_{\mathrm{rs}}$ for a population of vacuolate $M$. aeruginosa. E-S simulations were run for Chl $a$ between 20 and $1000 \mathrm{mg} \mathrm{m}^{-3}$ for vacuolate cells (see Sect. 4.1). $b_{\mathrm{b} \phi}^{*}$ was extended to $900 \mathrm{~nm}$ in order to facilitate computation of the MPH variable using the value 
at $750 \mathrm{~nm}$. Noise was introduced by randomly varying the concentration of TR and $a_{\mathrm{g}}(440)$ in the ranges 1 to $50 \mathrm{~g} \mathrm{~m}^{-3}$ and 0.5 to $5 \mathrm{~m}^{-1}$, respectively, inside the natural variability expected for Hartbeespoort (Matthews and Bernard, 2013). This tested the sensitivity of the empirical relationships to variations in background constituent concentrations.

Figure 10 shows the $R_{\mathrm{rs}}$ spectra and the resulting empirical relationships derived for the $710: 665$ ratio and the MPH variables. The best fit determined for the $710: 665$ ratio was

Chl $a=7.294 \times \exp ^{1.2739 \times\left(R_{\mathrm{rs}}(710) / R_{\mathrm{rs}}(665)\right)}, R^{2}=0.99$,

while that for the MPH variable was

Chl $a=222173 \mathrm{MPH}^{2}+5231.9 \mathrm{MPH}+14.625, R^{2}=1.0$.

The high correlation coefficients demonstrate the robustness of empirical-type algorithms for providing $\mathrm{Chl} a$ estimates in hypertrophic waters, as confirmed by the simulations. This confirms that empirical studies such as Schalles et al. (1998) and Matthews et al. (2012) have a strong bio-optical basis, provided that the dominant water constituent is phytoplankton (in this case the species tested is $M$. aeruginosa). The approach also demonstrates how empirical relationships derived from red/NIR optical signals might be species-specific since they are based on $b_{\mathrm{b} \phi}^{*}$. Therefore, empirically based algorithms are likely to be sensitive to species variability. The sensitivity study showed that the empirical relationships are stable despite variability in background concentrations of TR and gelbstoff.

\section{Conclusions}

The two-layered sphere model has facilitated in a simplified form the investigation of how a low-refractive-index particle (a gas vacuole) enclosed within a cell might impact the IOPs of M. aeruginosa. The two-layered model was capable of reproducing a number of features attributed to vacuoles: reduction in attenuation and the shift in the $\mathrm{Chl} a$ attenuation peak towards smaller wavelengths with increasing vacuolation, enlarged values for spectral backscattering particularly towards the red and NIR, decreased scattering in the forward direction noticeable as a dip towards smaller angles in the VSF, and an enlargement in the VSF between 30 and $60^{\circ}$. These findings confirm that gas vacuoles are responsible for these features and that the two-layer model is generally suitable as a first approximation for investigating the influence of gas vacuoles on IOPs in cyanobacteria. Sufficient closure between measured $R_{\mathrm{rs}}$ and that modelled using vacuolate two-layered spheres was obtained using chromatoplasm shell layer $1+\epsilon$ values between 1.1 and 1.14. The corresponding $b_{\mathrm{b} \phi}^{*}(510)$ values between 3.8 and $7.2 \times 10^{-3} \mathrm{~m}^{2} \mathrm{mg}^{-1}$ are in good agreement with those determined experimentally for M. aeruginosa (Zhou et al., 2012). Simulations using E-S showed how gas vacuolate cells cause the $R_{\mathrm{rs}}$ to be greatly enlarged relative to a population of cells modelled as homogeneous spheres. The changes in $R_{\mathrm{rs}}$ can be attributed to variable phytoplankton backscatter caused by intracellular structure (the gas vacuole). Empirical relationships for estimating $\mathrm{Chl} a$ in eutrophic/hypertrophic waters are robust even under variable tripton and gelbstoff concentrations, and are likely to be sensitive to species variability. In conclusion, gas vacuoles are one of the most important bio-optical substructures profoundly affecting the IOPs of cyanobacteria and leading to increased backscatter in particular towards the red/NIR, which may be distinctive to the genera.

Acknowledgements. The authors gratefully acknowledge the assistance of L. Robertson with Ecolight-S. For fieldwork assistance: T. Probyn, H. van Deventer, N. Slabbert. For funding M. W. Matthews: University of Cape Town and CSIR. The field work was supported by the Department of Water Affairs and the CSIR Safe Waters Earth Observations (SWEOS) research project. The authors also thank the two reviewers, who helped to strengthen the final version of the manuscript.

Edited by: E. Boss

\section{References}

Aas, E.: Refractive index of phytoplankton derived from its metabolite composition, J. Plankton Res., 18, 2223-2249, doi:10.1093/plankt/18.12.2223, 1996.

Aden, A. and Kerker, M.: Scattering of electromagnetic waves from two concentric spheres, J. Appl. Phys., 22, 1242-1246, 1951.

Agusti, S. and Phlips, E. J.: Light absorption by cyanobacteria: Implications of the colonial growth form, Limnol. Oceanogr., 37, 434-441, 1992.

Ahn, Y. H., Bricaud, A., and Morel, A.: Light backscattering efficiency and related properties of some phytoplankters, Deep-Sea Res., 39, 1835-1855, 1992.

Arakawa, E. T., Tuminello, P. S., Khare, B. N., and Milham, M. E.: Optical properties of ovalbumin in 0.130-2.50 microm spectral region, Biopolymers, 62, 122-128, doi:10.1002/bip.1004, 2001.

Bernard, S., Probyn, T. A., and Barlow, R. G.: Measured and modelled optical properties of particulate matter in the southern Benguela, S. Afr. J. Sci., 97, 410-420, 2001.

Bernard, S., Shillington, F. A., and Probyn, T. A.: The use of equivalent size distributions of natural phytoplankton assemblages for optical modeling, Opt. Express, 15, 1995-2007, 2007.

Bernard, S., Probyn, T. A., and Quirantes, A.: Simulating the optical properties of phytoplankton cells using a two-layered spherical geometry, Biogeosciences Discuss., 6, 1497-1563, doi:10.5194/bgd-6-1497-2009, 2009.

Bidigare, R. R., Schofield, O., and Prezelin, B. B.: Influence of zeaxanthin on quantum yield of photosynthesis of Synechococcus clone WH7803 (DC2)*, Mar. Ecol.-Prog. Ser., 56, 177-188, 1989.

Blank, C. E. and Sánchez-Baracaldo, P.: Timing of morphological and ecological innovations in the cyanobacteria - a key to understanding the rise in atmospheric oxygen, Geobiology, 8, 1-23, 2010 . 
Bricaud, A. and Morel, A.: Light attenuation and scattering by phytoplanktonic cells: a theoretical modeling, Appl. Optics, 25, 571580, 1986.

Bricaud, A., Morel, A., and Prieur, L.: Optical Efficiency Factors of Some Phytoplankters, Limnol. Oceanogr., 28, 816-832, 1983.

Bricaud, A., Bedhomme, A. L., and Morel, A.: Optical properties of diverse phytoplanktonic species: experimental results and theoretical interpretation, J. Plankt. Res., 10, 851-873, 1988.

Ciddor, P. E.: Refractive index of air: new equations for the visible and near infrared., Appl. Optics, 35, 1566-1573, 1996.

Clavano, W. R., Boss, E., and Karp-boss, L.: Inherent optical properties of non-spherical marine-like particles - from theory to observation, Oceanogr. Mar. Biol., 45, 1-38, 2007.

Dekker, A.: Detection of optical water quality parameters for eutrophic waters by high resolution remote sensing, Ph.D. thesis, Free University, the Netherlands, 1993.

Dekker, A. G., Vos, R. J., and Peters, S. W. M.: Comparison of remote sensing data, model results and in situ data for total suspended matter (TSM) in the southern Frisian lakes, Sci. Total Environ., 268, 197-214, 2001.

Doxaran, D., Cherukuru, N. C., Lavender, S. J., and Moore, G. F.: Use of a Spectralon panel to measure the downwelling irradiance signal: case studies and recommendations, Appl. Optics, 43, 5981-5986, 2004.

Dubelaar, G. B. and van der Reijden, C. S.: Size distributions of Microcystis aeruginosa colonies: a flow cytometric approach, Water Sci. Technol., 32, 171-176, 1995.

Dubelaar, G. B., Visser, J. W., and Donze, M.: Anomalous behaviour of forward and perpendicular light scattering of a cyanobacterium owing to intracellular gas vacuoles, Cytometry, 8, 405-412, doi:10.1002/cyto.990080410, 1987.

Dupouy, C., Neveux, J., Dirberg, G., Rottgers, R., Barboza Tenorio, M. M., and Ouillon, S.: Bio-optical properties of the marine cyanobacteria Trichodesmium spp., J. Appl. Remote Sens., 2, 117, doi:10.1117/1.2839036, 2008.

Fogg, G. E., Stewart, W. D. P., Fay, P., and Walsby, A. E.: Gas vacuoles, in: The blue-green algae, 93-110, Academic Press, London, 1973.

Fuhs, G.: Interferenzmikroskopische beobachtungen an den Polyphosphatkoerpern und gasvacuolen von cyanophyceen, Osterr. Bot. Z., 116, 411-422, 1969.

Ganf, G. G., Oliver, R. L., and Walsby, A. E.: Optical properties of gas-vacuolate cells and colonies of Microcystis in relation to light attenuation in a turbid, stratified reservoir (Mount Bold Reservoir, South Australia), Aust. J. Mar. Fresh. Res., 40, 595$611,1989$.

Golecki, J. R. and Drews, G.: Supramolecular organization and composition of membranes, in: The biology of cyanobacteria, edited by: Carr, N. G. and Whitton, B. A., 6, 125-142, Blackwell Scientific, Berkeley and Los Angeles, 1982.

Gregg, W. W. and Carder, K. L.: A simple spectral solar irradiance model for cloudless maritime atmospheres, Limnol. Oceanogr., 35, 1657-1675, 1990.

Hale, G. M. and Querry, M. R.: Optical Constants of Water in the 200-nm to 200-microm Wavelength Region, Appl. Optics, 12, 555-563, 1973.

Johnsen, G., Samset, O., Granskog, L., and Sakshaug, E.: In vivo absorption characteristics in 10 classes of bloom-forming phytoplankton : taxonomic characteristics and responses to photoadap- tation by means of discriminant and HPLC analysis, Mar. Ecol. Progr. Ser., 105, 149-157, 1994.

Jost, M. and Jones, D.: Morphological parameters and macromolecular organization of gas vacuole membranes of Microcystis aeruginosa Kuetz. emend. Elenkin, Can. J. Microbiol., 16, 159$164,1970$.

Jost, M. and Zehnder, A.: Die Gasvakuolen der Blaualge Microcystis aeruginosa, Schweiz Z. Hydrol., 28, 1-3, 1966.

Kirk, J. T. O.: A Theoretical Analysis of the Contribution of Algal Cells to the Attenuation of Light Within Natural Waters. II. Spherical Cells, New Phytol., 75, 21-36, 1975.

Kitchen, J. C. and Zaneveld, J. R. V.: A Three-Layered Sphere Model of the Optical Properties of Phytoplankton, Limnol. Oceanogr., 37, 1680-1690, 1992.

Lehmann, H. and Jost, M.: Kinetics of the assembly of gas vacuoles in the blue-green alga Microcystis aeruginosa Kuetz. emend. Elekin, Arch. Microbiol., 79, 59-68, 1971.

Matthews, M. W.: A current review of empirical procedures of remote sensing in inland and near-coastal transitional waters, Int. J. Remote Sens., 32, 6855-6899, doi:10.1080/01431161.2010.512947, 2011.

Matthews, M. W. and Bernard, S.: Characterizing the Absorption Properties for Remote Sensing of Three Small OpticallyDiverse South African Reservoirs, Remote Sensing, 5, 43704404, doi:10.3390/rs5094370, 2013.

Matthews, M. W., Bernard, S., and Winter, K.: Remote sensing of cyanobacteria-dominant algal blooms and water quality parameters in Zeekoevlei, a small hypertrophic lake, using MERIS, Remote Sens. Environ., 114, 2070-2087, 2010.

Matthews, M. W., Bernard, S., and Robertson, L.: An algorithm for detecting trophic status (chlorophyll-a), cyanobacterialdominance, surface scums and floating vegetation in inland and coastal waters, Remote Sens. Environ., 124, 637-652, doi:10.1016/j.rse.2012.05.032, 2012.

Meffert, M. E., Oberhäuser, R., and Overbeck, J.: Morphology and taxonomy of Oscillatoria redekei (Cyanophyta), Brit. Phycol. J., 16, 107-114, 1981.

Mitchell, B. G., Kahru, M., Wieland, J., and Stramska, M.: Determination of spectral absorption coefficients of particles, dissolved material and phytoplankton for discrete water samples, in: Ocean Optics Protocols For Satellite Ocean Color Sensor Validation, Revision 4, Volume IV: Inherent Optical Properties: Instruments, Characterizations, Field Measurements and Data Analysis Protocols, edited by: Mueller, J. L., Fargion, G. S., and McClain, C. R., chap. 4, National Aeronautical and Space Administration, Greenbelt, Maryland, 2003.

Morel, A. and Bricaud, A.: Inherent optical properties of algal cells including picoplankton: Theoretical and experimental results, Can. B. Fish. Aquat. Sci, 214, 521-559, 1986.

Morel, A., Ahn, Y.-H., Partensky, F., Vaulot, D., and Claustre, H.: Prochlorococcus and Synechococcus: A comparative study of their optical properties in relation to their size and pigmentation, J. Mar. Res., 51, 617-649, doi:10.1357/0022240933223963, 1993.

Mueller, J. L., Morel, A., Frouin, R., Davis, C., Arnone, R., Carder, K., Lee, Z., Steward, R., Hooker, S., Mobley, C. D., McLean, S., Holben, B., Miller, M., Pietras, C., Knobelspiesse, K. D., Fargion, G. S., Porter, J., and Voss, K.: Radiometric Measurements and Data Analysis Protocols, in: Ocean Optics Protocols For 
Satellite Ocean Color Sensor Validation, Revision 4, Volume III: edited by: Mueller J. L., Fargion, G. S., and McClain, C. R., vol. III, p. 78, NASA, Goddard Space Flight Space Center, Greenbelt, Maryland, 2003.

Ogawa, T., Sekine, T., and Aiba, S.: Reappraisal of the so-called light shielding of gas vacuoles in Microcystis Aeruginosa, Arch. Microbiol., 122, 57-60, 1979.

Petzold, T. J.: Volume scattering functions for selected ocean waters, Tech. rep., Scripps Institution of Oceanography Visibility Laboratory, San Diego, California, http://oai.dtic.mil/oai/oai?verb=getRecordl\&metadataPrefix= html $\&$ identifier=AD0753474, 1972.

Porter, J. and Jost, M.: Physiological effects of the presence and absence of gas vacuoles in the blue-green alga, Microcystis aeruginosa Kuetz. emend. Elenkin, Arch. Microbiol., 110, 225-231, 1976.

Quinby-Hunt, M., Hunt, A., Lofftus, K., and Shapiro, D.: Polarizedlight scattering studies of marine chlorella, Limnol. Oceanogr., 34, 1587-1600, 1989.

Quirantes, A. and Bernard, S.: Light-scattering methods for modelling algal particles as a collection of coated and/or nonspherical scatterers, J. Quant. Spectrosc. Ra., 100, 315-324, 2006.

Rajagopal, S., Sicora, C., Várkonyi, Z., Mustárdy, L., and Mohanty, P.: Protective effect of supplemental low intensity white light on ultraviolet-B exposure-induced impairment in cyanobacterium Spirulina platensis: formation of air vacuoles as a possible protective measure., Photosynth. Res., 85, 181-189, doi:10.1007/s11120-005-2439-6, 2005.

Randolph, K., Wilson, J., Tedesco, L., Li, L., Pascual, D. L., and Soyeux, E.: Hyperspectral remote sensing of cyanobacteria in turbid productive water using optically active pigments, chlorophyll a and phycocyanin, Remote Sens. Environ., 112, 40094019, 2008.

Raven, J. A.: The Role of Vacuoles, New Phytol., 106, 357-422, 1987.

Retalis, A., Hadjimitsis, D. G., Michaelides, S., Tymvios, F., Chrysoulakis, N., Clayton, C. R. I., and Themistocleous, K.: Comparison of aerosol optical thickness with in situ visibility data over Cyprus, Nat. Hazards Earth Syst. Sci., 10, 421-428, doi:10.5194/nhess-10-421-2010, 2010.

Reynolds, C. S., Jaworski, G. H. M., Cmiech, H. A., and Leedale, G. F.: On the annual cycle of the blue-green alga microcystis aeruginosa kutz. Emend. Elenkin, Philos. T. Roy. Soc. B, 293, 419-477, 1981.

Robarts, A. R. D., Zohary, T., and Robarts, R. D.: Microcystis aeruginosa and underwater light attenuation in a hypertrophic lake (Hartbeespoort Dam, South Africa), J. Ecol., 72, 10011017, 1984.

Roesler, C.: Theoretical and experimental approaches to improve the accuracy of particulate absorption coefficients derived from the quantitative filter technique, Limnol. Oceanogr. 43, 16491660, 1998.

Rottgers, R., Doerffer, R., McKee, D., and Schonfeld, W.: Algorithm Theoretical Basis Document: The Water Optical Properties Processor (WOPP), Tech. rep., Helmholtz-Zentrum Geesthacht, University of Strathclyde, Geesthacht, 2011.

Sartory, D. P. and Grobbelaar, J. U.: Extraction of chlorophyll a from freshwater phytoplankton for spectrophotometric analysis, Hydrobiologia, 114, 177-187, 1984.
Schalles, J. F., Gitelson, A. A., Yacobi, Y. Z., and Kroenke, A. E.: Estimation of chlorophyll a from time series measurements of high spectral resolution reflectance in an eutrophic lake, J. Phycol., 34, 383-390, 1998.

Schreurs, R.: Light scattering by algae: fitting experimental data using Lorenz-Mie theory, Ph.D. thesis, Vrije University, Amsterdam, 1996.

Shear, H. and Walsby, A. E.: An investigation into the possible lightshielding role of gas vacuoles in a planktonic blue-green alga, Eur. J. Phycol., 10, 241-251, doi:10.1080/00071617500650231, 1975.

Smith, R. and Peat, A.: Comparative structure of the gas-vacuoles of blue-green algae, Arch. Microbiol., 57, 111-122, 1967.

Spinrad, R. W. and Brown, J. F.: Relative real refractive index of marine microorganisms: a technique for flow cytometric estimation, Appl. Optics, 25, 1930-1934, 1986.

Stramski, D. and Wozniak, S. B.: On the role of colloidal particles in light scattering in the ocean, Limnol. Oceanogr., 50, 1581-1591, 2005.

Stramski, D., Bricaud, A., and Morel, A.: Modeling the inherent optical properties of the ocean based on the detailed composition of the planktonic community, Appl. Optics, 40, 2929-2945, 2001.

Svensen, O., Frette, O., and Erga, S. R.: Scattering properties of microalgae: the effect of cell size and cell wall, Appl. Optics, 46, 5762-5769, 2007.

Toon, O. B. and Ackerman, T. P.: Algorithms for the calculation of scattering by stratified spheres, Appl. Optics, 20, 3657-3660, 1981.

Vaillancourt, R. D.: Light backscattering properties of marine phytoplankton: relationships to cell size, chemical composition and taxonomy, J. Plankt. Res., 26, 191-212, doi:10.1093/plankt/fbh012, 2004.

van baalen, C. and Brown, R. M.: The ultrastructure of the marine blue green alga, Trichodesmium erythraeum, with special reference to the cell wall, gas vacuoles, and cylindrical bodies, Arch. Hydrobiol., 69, 79-91, 1969.

van Liere, L. and Walsby, A. E.: Interactions of cyanobacteria with light, in: The biology of cyanobacteria, edited by: Carr, N. G. and Whitton, B. A., chap. 2, 9-46, Blackwell Scientific, Berkeley and Los Angeles, 1982.

Volten, A. H., Haan, J. F. D., Hovenier, J. W., Schreurs, R., Vassen, W., Dekker, A. G., Hoogenboom, J., Charlton, F., and Wouts, R.: Laboratory Measurements of Angular Distributions of Light Scattered by Phytoplankton and Silt, Limnol. Oceanogr., 43, 1180-1197, 1998.

Šmarda, J.: Cell ultrastructure changes accompanying the annual life cycle of the cyanobacterium Microcystis aeruginosa, Algological Studies, 130, 27-38, doi:10.1127/1864-1318/2009/01300027, 2009.

Waaland, J. R., Waaland, S. D., and Branton, D.: Gas vacuoles: Light shielding in blue-green algae, J. Cell Biol., 48, 212-215, 1971.

Walsby, A. E.: Gas vesicles, Microbiol. Rev., 58, 94-144, doi:10.1016/j.tim.2006.01.002, 1994.

Wang, Q., Sun, D., Li, Y., Le, C., and Huang, C.: Mechanisms of Remote-Sensing Reflectance Variability and Its Relation to Bio-Optical Processes in a Highly Turbid Eutrophic Lake: Lake Taihu (China), IEEE T. Geosci. Remote, 48, 575-584, doi:10.1109/TGRS.2009.2027316, 2010. 
Whitmire, A. L., Pegau, W. S., Karp-boss, L., Boss, E., and Cowles, T. J.: Spectral backscattering properties of marine phytoplankton cultures, Opt. Express, 18, 1680-1690, doi:10.1364/OE.18.015073, 2010.

Witkowski, K., Krol, T., Zielinski, A., and Kuten, E.: A LightScattering Matrix for Unicellular Marine Phytoplankton, Limnol. Oceanogr., 43, 859-869, 1998.

Zhang, X., Lewis, M., Lee, M., Johnson, B., and Korotaev, G.: The volume scattering function of natural bubble populations, Limnol. Oceanogr. 47, 1273-1282, doi:10.4319/lo.2002.47.5.1273, 2002.
Zhang, Y., Yin, Y., Wang, M., and Liu, X.: Effect of phytoplankton community composition and cell size on absorption properties in eutrophic shallow lakes : field and experimental evidence, Opt. Express, 20, 11882-11898, doi:10.1364/OE.20.011882, 2012.

Zhou, W., Wang, G., Sun, Z., Cao, W., Xu, Z., Hu, S., and Zhao, J.: Variations in the optical scattering properties of phytoplankton cultures, Opt. Express, 20, 11189-11206, 2012.

Zimba, P. V. and Gitelson, A.: Remote estimation of chlorophyll concentration in hyper-eutrophic aquatic systems: Model tuning and accuracy optimization, Aquaculture, 256, 272-286, 2006. 